\title{
Mountain-Wave Turbulence Encounter of the Research Aircraft HALO above Iceland
}

\author{
Martina Bramberger, ${ }^{\mathrm{a}}$ Andreas Dörnbrack, Henrike Wilms, \\ AND FLORIAN EWALD \\ Deutsches Zentrum für Luft- und Raumfahrt, Institut für Physik der Atmosphäre, Weßling, Germany \\ ROBERT SHARMAN \\ National Center for Atmospheric Research, Boulder, Colorado
}

(Manuscript received 31 March 2019, in final form 30 October 2019)

\begin{abstract}
Strong turbulence was encountered by the German High-Altitude Long-Range Research Aircraft (HALO) at flight level $430(13.8 \mathrm{~km})$ on 13 October 2016 above Iceland. In this event the turbulence caused altitude changes of the research aircraft of about $50 \mathrm{~m}$ within a period of approximately $15 \mathrm{~s}$. Additionally, the automatic thrust control of the HALO could not control the large gradients in the horizontal wind speed and, consequently, the pilot had to switch off this system. Simultaneously, the French Falcon of Service des Avions Français Instrumentés pour la Recherche en Environnement (SAFIRE), flying $2 \mathrm{~km}$ below HALO, also encountered turbulence at almost the same location. On that day, mountain-wave (MW) excitation and propagation was favored by the alignment of strong surface winds and the polar front jet. We use a combination of in situ observations, ECMWF and empirical turbulence forecasts, and high-resolution simulations to characterize the observed turbulent event. These show that a pronounced negative vertical shear of the horizontal wind favored overturning and breaking of MWs in the area of the encountered turbulence. The turbulent region was tilted upstream and extended over a distance of about $2 \mathrm{~km}$ in the vertical. The analyses suggest that HALO was flying through the center of a breaking MW field while the French Falcon encountered the lower edge of this region. Surprisingly, the pronounced gradients in the horizontal wind speeds leading to the deactivation of the automatic thrust control were located north of the breaking MW field. In this area, our analysis suggests the presence of gravity waves that could have generated the encountered modulation of the horizontal wind field.
\end{abstract}

\section{Introduction}

Mountain waves (MWs) are generated by stratified flow over topography and influence the atmosphere on different scales ranging from hundreds of kilometers down to turbulence scales (e.g., reviews of Smith 1989; Fritts and Alexander 2003). On large scales, MWs affect the general atmospheric circulation by transport of momentum and wave drag, while on smaller scales, the breaking of MWs considerably influences the atmosphere, for example, in downslope windstorms (e.g.,

\footnotetext{
${ }^{a}$ Current affiliation: NorthWest Research Associates, Boulder, Colorado.
}

Corresponding author: Martina Bramberger, martina.bramberger@ dlr.de
Peltier and Clark 1979), vertical mixing of, for example, water vapor or aerosols (Dörnbrack and Dürbeck 1998; Heller et al. 2017), potential vorticity generation (Schär and Smith 1993), and upscale forcing (Thorpe et al. 1993; Aebischer and Schär 1998). In aviation the turbulence generated by breaking MWs [mountain-wave turbulence (MWT)] is a well-acknowledged hazard (e.g., Sharman et al. 2012b).

In this context, the unexpected turbulence due to, for example, breaking MWs (MWT) is considered to be the cause of numerous injuries to passengers and crew in aviation (Sharman and Pearson 2017). Additionally, frequent turbulence encounters can lead to enhanced aircraft fatigue and damage. Therefore, MWT is not only a safety issue in aviation but can also lead to increased operational costs of airlines (Sharman et al. 2012b). 
MW breaking can be caused by different mechanisms. On the one hand, decreasing density (Hines 1960; Lindzen 1967) and/or reverse wind shear can lead to increasing MW amplitudes with altitude (Smith 1989). These increased amplitudes enhance steepening, overturning and subsequently the breaking of vertically propagating MWs. This process is of particular importance at higher altitudes as, for example, in the stratosphere or mesosphere (e.g., Bacmeister and Schoeberl 1989; Fritts and Alexander 2003). Increasing static stability as, for example, across the tropopause, on the other hand, reduces the vertical wavelength of propagating MWs, which in turn again enhances the potential of MW breaking (VanZandt and Fritts 1989). Furthermore, MW breaking can be caused by so-called critical layers where the wave phase speed equals the horizontal wind speed projected along the horizontal wave vector (e.g., Clark and Peltier 1984; Dörnbrack 1998).

Due to their importance to the general atmospheric circulation, numerous campaigns were conducted to characterize MWs (e.g., Bougeault et al. 1990, 1993, 2001; Grubišić et al. 2008; Fritts et al. 2016). Therefore, a large number of observational studies exist where the characteristics of propagating MWs are well documented. However, direct observations of the breaking of MWs are still relatively rare (Doyle et al. 2005; Sharman et al. 2012b). A well-established study is the observation of the windstorm and wave breaking in the lee of the Front Range of the Rocky Mountains on 11 January 1972 (Lilly and Zipser 1972; Lilly 1978). More recent studies comprise, for example, an MW breaking event above the Front Range of the Rocky Mountains where severe clear-air turbulence (CAT) was encountered by a DC-8 cargo jet (Clark et al. 2000) or breaking MWs above the central Alps (Jiang and Doyle 2004), the Welsh mountains (Worthington 1998), and Greenland (Doyle et al. 2005; Sharman et al. 2012a).

Recently, state-of-the-art numerical weather prediction (NWP) models attained horizontal resolutions of less than $10 \mathrm{~km}$. In that context the recent increase of horizontal resolution of the Integrated Forecast System (IFS) of the European Centre for Medium-Range Weather Forecasts (ECMWF) led to a realistic simulation of wave-induced mesoscale temperature anomalies (Dörnbrack et al. 2017). However, in a multimodel study low predictability especially of stratospheric MW breaking was found (Doyle et al. 2011). Although using the same initial states and a sophisticated set of different high-resolution numerical models with a horizontal resolution of $1 \mathrm{~km}$, the results of these models showed marked differences (Doyle et al. 2011). These differences increased with the introduction of a larger mountain height. The found diversity of model results was attributed to differences in the dynamical cores of the numerical models.

However, to provide operational turbulence forecasts the Graphical Turbulence Guidance tool (GTG) predicts aircraft-type-independent turbulence by calculating a set of diagnostics, such as, for example, the Ellrod I index (Ellrod and Knapp 1992), from NWP forecasts (Sharman et al. 2006; Sharman and Pearson 2017). These applied diagnostics reflect a variety of turbulencegenerating processes in the atmosphere. The GTG approach takes further into account that the breaking of MWs is a well-known hazard to aviation (e.g., Bacmeister et al. 1990; Schmid and Dörnbrack 1999; Leutbecher and Volkert 2000; Sharman et al. 2012b; Sharman and Pearson 2017). Therefore, two forecasts are generated by the GTG, one for CAT and the other for MWT. In this context MWT forecasts are produced by a simple multiplication of the CAT prediction with a terrain-dependent factor. Recently this approach was implemented at the World Area Forecasting System (WAFS) to provide operational global turbulence forecasts for aviation (Kim et al. 2018).

In the present study, we analyze a strong turbulence encounter of the High-Altitude Long-Range Research Aircraft (HALO) during the North Atlantic Waveguide and Downstream Impact Experiment (NAWDEX) on 13 October 2016 (Schäfler et al. 2018). The event took place in the lower stratosphere at an altitude of about $14 \mathrm{~km}$ above Iceland. The flight leg was coordinated with the Service des Avions Français Instrumentés pour la Recherche en Environnement (SAFIRE) Falcon, which flew about $2 \mathrm{~km}$ below HALO along the same flight track at nearly the same time. Thus, for this study, almost simultaneous in situ observations of a turbulent flow field at different altitudes are available.

With the dataset at hand, the analysis of this case study addresses the following questions: What atmospheric process caused the encountered turbulence event? Can 2D numerical simulations reproduce essential features of the observed turbulence to analyze the generation mechanism? How well was this event predicted by the GTG? How did the research aircraft react to this event? How strong was the encountered turbulence?

In the following, first the applied methods and models are described in section 2. Afterward, the analyzed incident is introduced in section 3 and an overview on the general atmospheric conditions relevant for MW excitation and propagation is presented in section 4 . Section 5 gives a detailed analysis of aircraft in situ measurements, followed by a comparison of these observations to ECMWF IFS and GTG forecasts in section 6. Finally, results of 2D Euler-Lagrangian 
(EULAG) simulations are presented in section 7, and the discussion with conclusions in section 8 concludes this paper.

\section{Methods and model description}

\section{a. Analysis of in situ measurements}

\section{1) Flux CAlculation}

For this case study HALO in situ measurements of all three wind components and the temperature as well as the pressure are available (Giez et al. 2016). A detailed description how the components of the wind speed are derived from in situ measurements can be found in Mallaun et al. (2015). Here, we use data sampled at $10 \mathrm{~Hz}$ with a horizontal resolution of about $25 \mathrm{~m}$ on a flight leg with a length of about $500 \mathrm{~km}$. From these measurements the vertical energy flux $\mathrm{EF}_{z}$ and the vertical fluxes of horizontal momentum $\mathrm{MF}_{x}$ and $\mathrm{MF}_{y}$ are derived applying two different approaches (see also Bramberger et al. 2018). On the one hand, leg-integrated values of $\mathrm{MF}_{x}$ and $\mathrm{MF}_{y}$ are calculated by

$$
\mathrm{MF}_{x}=\frac{\bar{\rho}}{s} \int_{0}^{s} u^{\prime} w^{\prime} d s \quad \mathrm{MF}_{y}=\frac{\bar{\rho}}{s} \int_{0}^{s} v^{\prime} w^{\prime} d s,
$$

in units of $\mathrm{Pa}$, and of $\mathrm{EF}_{z}$ by

$$
\mathrm{EF}_{z}=\frac{1}{s} \int_{0}^{s} p^{\prime} w^{\prime} d s
$$

in units of $\mathrm{W} \mathrm{m}^{-2}$, according to Smith et al. (2008). Here, $\bar{\rho}$ denotes the mean density along the leg and primed quantities denote perturbations of the respective parameter. $\mathrm{MF}_{x}$ and $\mathrm{MF}_{y}$ are the zonal and meridional components of the vertical momentum flux vector MF. The pressure $p$ used for calculating $\mathrm{EF}_{z}$ was hydrostatically corrected; for further information see Smith et al. $(2008,2016)$. The perturbation quantities $u^{\prime}, v^{\prime}, w^{\prime}$, and $p^{\prime}$ are calculated from the flight-level data $u, v, w$, and $p$ by subtracting linear least squares fits (Bramberger et al. 2017, 2018). This approach removes large-scale gradients, for example, when HALO is crossing synoptic-scale weather systems. These fluxes will be referred to as leg-integrated fluxes in the following.

The second approach assesses the spatial variability of the energy and momentum fluxes as well as the distribution of energy to different scale ranges. This was done to analyze whether the linearity of MW propagation depends on the respective scales. For this analysis, a bandpass filter is applied to the data to separate the turbulent scales $\left(\lambda_{h} \leq 5 \mathrm{~km}\right)$ from the mountain-wave scales $\left(20<\lambda_{h}<70 \mathrm{~km}\right)$. The scales were separated with wavelet analysis by reconstructing signals of the respective wavelength ranges from these wavelets. In the following, these fluxes are referred to as scale-separated fluxes. For this analysis the fluxes are calculated by

$$
\begin{aligned}
\mathrm{EF}_{z} & =\overline{p^{\prime} w^{\prime}}, \\
\mathrm{EF}_{z M} & =-\bar{\rho}\left(\bar{u} \times \overline{u^{\prime} w^{\prime}}+\bar{v} \times \overline{v^{\prime} w^{\prime}}\right), \quad \text { and } \\
\mathrm{HF} & =c_{p} \rho \times \overline{\theta^{\prime} w^{\prime}},
\end{aligned}
$$

where the overbars represent a moving average over $10 \mathrm{~km}$ of the already filtered and reconstructed data, and $\bar{u}$ and $\bar{v}$ are the mean zonal and meridional wind speeds over the complete flight leg. The vertical heat flux HF is calculated with the perturbation of the potential temperature $\theta$ and the specific heat at constant pressure $c_{p}=1004 \mathrm{~J} \mathrm{~K}^{-1} \mathrm{~kg}^{-1}$. The averages of the scaleseparated momentum and energy fluxes differ from the leg-integrated fluxes since different scales are captured by the two methods.

Assuming nondissipative, freely vertically propagating internal gravity waves in a steady flow, we use the Eliassen-Palm relation to test the linearity of the sampled wave field (Eliassen and Palm 1961). For MWs this relation is given by

$$
\mathrm{EF}_{z}=-\left(\bar{u} \times \mathrm{MF}_{x}+\bar{v} \times \mathrm{MF}_{y}\right) \equiv \mathrm{EF}_{z M} .
$$

The product on the right-hand side of horizontal wind speed and vertical flux of horizontal momentum $\left(\mathrm{EF}_{z M}\right)$ will be referred to as UMF.

\section{2) WAVELET ANALYSIS OF MOUNTAIN WAVES}

Wavelet spectra (Torrence and Compo 1998) are employed for the spectral analysis of the energy fluxes of the observed mountain waves. Following Woods and Smith (2010), the Morlet wavelet of order 6 is used as the mother wavelet and the cospectra of the energy, momentum, and heat fluxes are calculated with

$$
\begin{aligned}
\widetilde{\mathrm{EF}}_{n}\left(s_{j}\right) & =\Re\left\{\tilde{P}_{n}\left(s_{j}\right) \tilde{W}_{n}^{*}\left(s_{j}\right)\right\}, \\
\widetilde{\mathrm{MF}}_{x n}\left(s_{j}\right) & =\bar{\rho} \times \Re\left\{\tilde{U}_{n}\left(s_{j}\right) \tilde{W}_{n}^{*}\left(s_{j}\right)\right\}, \quad \text { and } \\
\widetilde{\mathrm{HF}}_{n}\left(s_{j}\right) & =\Re\left\{\tilde{\theta}_{n}\left(s_{j}\right) \tilde{W}_{n}^{*}\left(s_{j}\right)\right\},
\end{aligned}
$$

where $\Re$ denotes the real part, and the quantities $\tilde{P}_{n}\left(s_{j}\right)$, $\tilde{\theta}_{n}\left(s_{j}\right)$, and $\tilde{U}_{n}\left(s_{j}\right)$ are the wavelet transforms of $p^{\prime}, u^{\prime}$, and the perturbation of the potential temperature $\theta^{\prime}$ at spatial index $n$ for the wavelet scale $s_{j}$ at wavenumber index $j$. $\tilde{W}_{n}^{*}\left(s_{j}\right)$ denotes the complex conjugate of the wavelet 
transform of $w^{\prime}$ and $\widetilde{\mathrm{HF}}_{n}\left(s_{j}\right)$ is the cospectrum of the vertical heat flux.

\section{3) Turbulence PARAMETERS TKE AND EDR}

Following Bramberger et al. (2018) two parameters are derived from in situ aircraft observations to characterize atmospheric turbulence at flight level: the turbulent kinetic energy (TKE) and the cube root of the energy dissipation rate $\left(\mathrm{EDR} ; \varepsilon^{1 / 3}\right)$. As the EDR can be related to aircraft-specific loads it can be calibrated to different aircraft types in terms of aircraft response (MacCready 1964; Cornman et al. 1995; Sharman et al. 2014; Cornman 2016). Therefore, it is a commonly used parameter to determine aviation turbulence intensity. Moreover, the International Civil Aviation Organization (ICAO 2001) uses EDR as standard for aviation turbulence reporting. Here, the thresholds to determine turbulence intensity (light, moderate, severe, extreme) are approximates based on the pilot report (PIREP)-EDR curves from Fig. 7 of Sharman et al. (2014) for a small business jet weight category.

The TKE per unit mass is calculated by TKE $=$ $\left(\sigma_{u_{\mathrm{ac}}}^{2}+\sigma_{v_{\mathrm{ac}}}^{2}+\sigma_{w}^{2}\right) / 2$, that is, as half the sum of the variances of the wind fluctuations along the leg. For our analysis the TKE is calculated for different subleg lengths ranging between about 16 and $4 \mathrm{~km}$.

As in Strauss et al. (2015) and Bramberger et al. (2018) the calculation of EDR is based on the inertial dissipation technique (IDT; Champagne 1978; Piper and Lundquist 2004; Večenaj et al. 2012), a method that takes into account the Kolmogorov form of the turbulent energy spectrum. In this framework, the spectral energy density $S_{i}$ for the respective component of the wind velocity vector in aircraft coordinates $u_{i}=\left\{u_{\mathrm{ac}}, v_{\mathrm{ac}}, w\right\}$ is given by

$$
S_{i}(k)=\alpha_{i} \varepsilon^{2 / 3} k^{-5 / 3},
$$

where $k$ is the wavenumber, $i$ is the index of the respective component of the wind velocity vector, and $\alpha_{i}=\{0.53,0.707,0.707\}$ are the Kolmogorov constants for $u_{\mathrm{ac}}, v_{\mathrm{ac}}$, and $w$, respectively (Oncley et al. 1996; Piper and Lundquist 2004; Strauss et al. 2015). With the help of Eq. (10), the EDR can be computed from the spectrum of each wind velocity component $u_{i}$ by

$$
\operatorname{EDR}_{i}=\varepsilon_{i}^{1 / 3}=\left[\overline{\frac{S_{i}(k) k^{5 / 3}}{\alpha_{i}}}\right]^{1 / 2} .
$$

For this study the complete flight leg is divided into overlapping sublegs with a length of $4 \mathrm{~km}$ and the spectra are averaged over three segments. Note, the

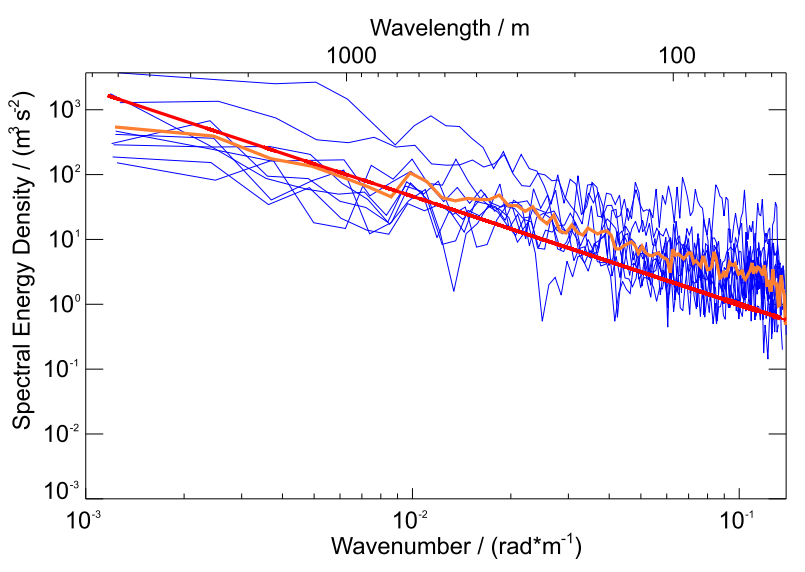

FIG. 1. Power spectral density of the vertical wind speed for the $4 \mathrm{~km}$ sublegs at and around the turbulence encounter between $64.8^{\circ}$ and $65.7^{\circ} \mathrm{N}$. The red line shows the Kolmogorov $-5 / 3$ and the orange line denotes the mean over all shown sublegs.

quantity $S_{i}$ used to calculate EDR according to Eq. (11) is an arithmetic mean of the spectral energy densities over these three overlapping segments that is denoted by the overbar. Furthermore, we define a fixed frequency range within which EDR is calculated between 0.1 and $3.5 \mathrm{~Hz}$. This fixed frequency range is a compromise between taking into account as much data as possible with less variance in the spectral slope but excluding artifacts that could be due to aliasing, digital noise or other sources. During the turbulence encounter this slope is -1.41 with a variance of 0.21 (Fig. 1).

A geometric mean over all $\operatorname{EDR}_{i}(\overline{\mathrm{EDR}}=$ $\sqrt[3]{\left.\mathrm{EDR}_{u_{\mathrm{ac}}} \cdot \mathrm{EDR}_{v_{\mathrm{ac}}} \cdot \mathrm{EDR}_{w}\right)}$ is employed to estimate the average EDR over all three wind components.

\section{b. Numerical models}

To complement and gain further insight in the atmospheric processes involved, numerical models are taken into account. These models comprise the ECMWF IFS, EULAG, and, as a diagnostic tool, the GTG.

\section{1) ECMWF IFS}

To describe the synoptic situation during the research flight, hourly short-term forecasts and six-hourly operational analyses of the deterministic high-resolution IFS runs are combined to generate a continuous dataset for the flights of both aircraft. The IFS model is a global, hydrostatic semi-implicit, semi-Lagrangian NWP model. During the NAWDEX campaign, ECMWF cycle 41r2 was operational (Hólm et al. 2016).

The corresponding high-resolution analyses and forecasts are computed on a cubic octahedral grid with $\Delta x \approx 9 \mathrm{~km}$ while the spectral truncation remained at 
wavenumber 1279 ( $T_{\mathrm{Co}} 1279$; Malardel and Wedi 2016). ${ }^{1}$ In the vertical, 137 levels range from the model top at a pressure level of $0.01 \mathrm{hPa}(\approx 80 \mathrm{~km}$ altitude) down to the surface ( $\approx 10 \mathrm{~m}$ altitude). In the lower stratosphere, the vertical resolution is about $500 \mathrm{~m}$.

Based on the ECMWF IFS operational analyses at 1200 UTC the Scorer parameter is approximated by

$$
\ell_{U}^{2}=\frac{N^{2}}{U^{2}}
$$

with the static stability $N$ and the horizontal wind $U=\sqrt{u^{2}+v^{2}}$.

\section{2) GTG}

Turbulence forecasts of the GTG are calculated from the operational IFS short-term forecasts where the forecast parameter is the EDR. The way the GTG is designed, it uses the output fields of the IFS for diagnosing turbulence. Consequently, the GTG depends on the scale of the input NWP and cannot resolve turbulence by itself.

Instead, the GTG uses an ensemble of multiple CAT diagnostics describing different physical processes. This approach is based on the assumption that a downscale cascade from the larger resolved scales to the aircraft scales exists. In a last step the different diagnostic quantities are projected to one common, aircraft typeindependent forecast parameter, the EDR.

In general, the GTG turbulence forecast products consist of two parameters: CAT and MWT. In the GTG framework the term CAT is used in a more general way and includes any diagnostic that successfully identifies large spatial gradients of atmospheric state parameters, regardless of their generation mechanism or their location with respect to clouds. That way, the CAT diagnostic also includes other sources apart from KelvinHelmholtz instabilities such as, for example, convective systems. To forecast MWT, the GTG multiplies the CAT diagnostics with a parameter related to the terrain height and low-level wind speed [Sharman and Pearson 2017, their Eq. (7)]. A detailed description of the GTG and its statistical forecast skill can be found in Sharman et al. (2006) and Sharman and Pearson (2017).

\section{3) EULAG}

EULAG (Prusa et al. 2008) ${ }^{2}$ is a multiscale computational model for the simulation of geophysical flows. In the version used for this study it solves the anelastic equations (Prusa et al. 2008).

\footnotetext{
${ }^{1}$ See Wedi (2014) and Malardel and Wedi (2016) for more explanation about linear and cubic grids.

${ }^{2}$ http://www2.mmm.ucar.edu/eulag/.
}

To analyze in principal the generation mechanism of the strong turbulence encountered above Iceland, a 2D configuration of EULAG is employed where subgridscale motions are treated via an implicit large-eddy simulation (ILES) scheme (Grinstein et al. 2007). For this case study, a fine grid spacing is necessary to resolve the breaking of MWs and the associated turbulence. Therefore, a 2D setup was chosen to limit computational demands. Here, the computational grid is centered at the turbulence encounter and consists of $3456 \times 251$ data points in the horizontal and vertical, respectively. The resolution is $200 \mathrm{~m}$ in the horizontal and $100 \mathrm{~m}$ in the vertical with a time step of $2 \mathrm{~s}$. Viscosity and Coriolis terms are disregarded in the applied setup. The sponge layer covers laterally $50 \mathrm{~km}$ and vertically the uppermost $8 \mathrm{~km}$ of the simulation domain with an absorber time scale of $200 \mathrm{~s}$ in the horizontal direction and $180 \mathrm{~s}$ in the vertical direction, respectively. Initial and boundary conditions are taken from ECMWF operational analysis at 1200 UTC at an upstream position close to the coast of Iceland. Furthermore, the topography is taken from ECMWF and is interpolated onto the flight track.

\section{c. Lidar and radar measurements}

The lidar observations presented in this study were done with the Water Vapor Lidar Experiment in Space (WALES) instrument. The instrument is a combined airborne high-spectral-resolution (HSRL; Esselborn et al. 2008) and water vapor differential absorption lidar system (Wirth et al. 2009). The HSRL operates at $532 \mathrm{~nm}$ and allows the direct measurement of aerosol and cloud particle backscatter. With a vertical resolution of $15 \mathrm{~m}$ and a typical horizontal resolution of $200 \mathrm{~m}$, the nadir looking instrument provides profiles of the backscatter ratio, which is defined as the ratio of total to molecular backscatter intensity. With its high sensitivity to small cloud particles, WALES is well suited to detect the presence and the height of optically thin clouds.

The radar observations were made with a MIRA-36 (Melchionna et al. 2008), which is part of the HALO Microwave Package (HAMP; Mech et al. 2014). This instrument is a monostatic pulsed Doppler cloud radar operating at $35.5 \mathrm{GHz}$. In contrast to the lidar, the cloud radar can penetrate optically thick clouds composed of water drops or large ice crystals. Coaligned with the lidar, the nadir looking radar thus complements the cloud observations made from HALO. For more information on this instrument please refer to Mech et al. (2014).

\section{Incident}

The multipurpose research flight number 10 (RF10) on 13 October 2016 during the NAWDEX campaign 
a)

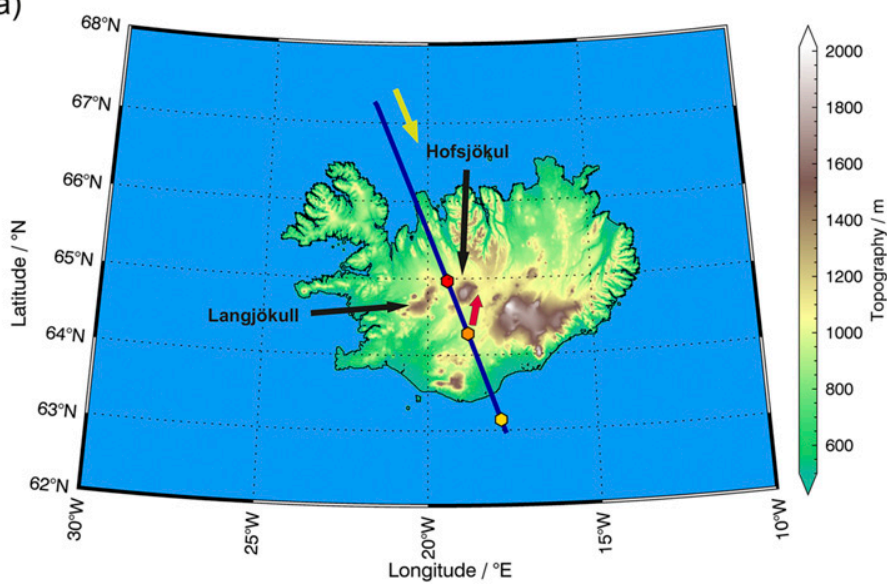

b)

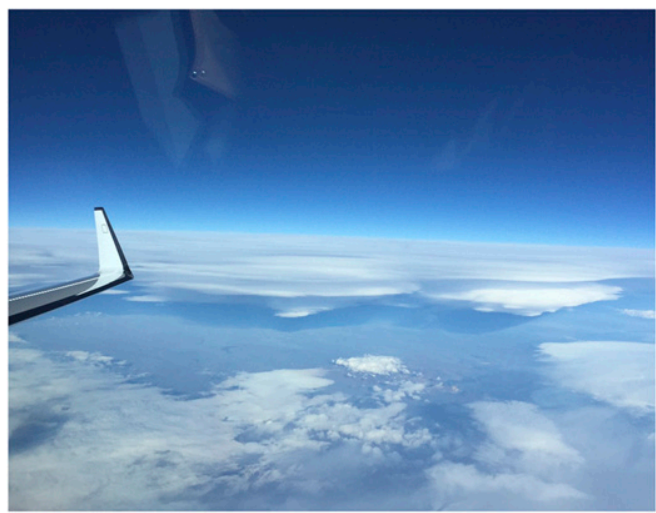

FIG. 2. (a) HALO's flight track above Iceland. Red dot shows the position of the turbulence encounter, the orange dot refers to the position where the photograph in (b) is taken and the yellow dot indicates the position of the upstream profiles. The yellow arrow indicates the flight direction from north to south and the red arrow the approximate viewing direction of the photograph in (b), respectively. The French Falcon flew nearly simultaneously along the same track at an altitude of $11.8 \mathrm{~km}(2 \mathrm{~km}$ underneath HALO). (b) Photograph taken from HALO's cockpit after turbulence encounter above Iceland (courtesy of Steffen Gemsa)

took HALO along the edge of an upper-level ridge from Iceland, across Spitsbergen to Norway and back to Iceland. This flight was designed to observe several atmospheric phenomena as, for example, CAT, tropopause structure, and MWs. Therefore, the flight also included one leg above Iceland intended to observe MWs that was coordinated with the French research aircraft Falcon from SAFIRE.

However, during its first passage over Iceland at flight level 430 (about $13.8 \mathrm{~km}$, Fig. 2a), HALO encountered strong turbulence above Iceland at 1453 UTC. Due to flight safety reasons the intended MW leg was skipped, and HALO returned to Keflavik afterward. Regarding the incident the commanding pilot reported strong turbulence and altitude changes of about $100 \mathrm{ft}$. Additionally, he found it necessary to deactivate the automatic thrust control as it could not control the rapid speed changes.

First analysis of the pictures taken by the pilots in the cockpit looking backward reveals multiple cloud systems above Iceland (Fig. 2b). In this picture lenticularis and cumuli clouds are visible. These cloud structures can be attributed to different atmospheric processes as, for example, convection or MWs.

\section{Ambient conditions for MW excitation and propagation}

\section{a. ECMWF operational forecasts and analysis}

On 13 October 2016, a surface low pressure system was present east of Greenland together with a pronounced surface high pressure system above and north of Scandinavia (see Fig. 3a). As Iceland was located between these systems, strong horizontal surface winds up to about $15 \mathrm{~m} \mathrm{~s}^{-1}$ were present with a southsoutheasterly (SSE) direction. This wind direction favored the excitation of MWs at the main mountain ridges of Iceland (i.e., Vatnajökull, Langjökull, and Hofsjökull). Consequently, the geopotential height undulates above Iceland due to the mountain-wave activity. Between 1200 and 1800 UTC the positions of the low and high pressure systems remain nearly stationary and the horizontal wind speed decreases slightly by about $2 \mathrm{~m} \mathrm{~s}^{-1}$ (see Fig. 3b). However, the horizontal wind direction veers anticlockwise and becomes more southeasterly.

In the upper troposphere, the meteorological situation was similar to the surface with a low pressure system west of Iceland and a high pressure system to the east (see Fig. 3c). However, the upper-level trough is more elongated and stretches from Greenland toward southeast to the North Atlantic. The ridge is located more to the north, right between Scandinavia and Iceland. Therefore, the southerly polar front jet was located above Iceland with almost the same wind direction as the surface jet with attained values of about $55 \mathrm{~m} \mathrm{~s}^{-1}$. The research aircraft HALO flew along this jet from northwest to southeast with a flight direction that was nearly aligned but opposite to the mean wind direction. During the afternoon, horizontal wind speeds decreased from about 40 to $30 \mathrm{~m} \mathrm{~s}^{-1}$ in the upper troposphere above Iceland as the polar front jet propagated farther to the west associated with the ridge extending farther west (see Fig. 3d). 
a)
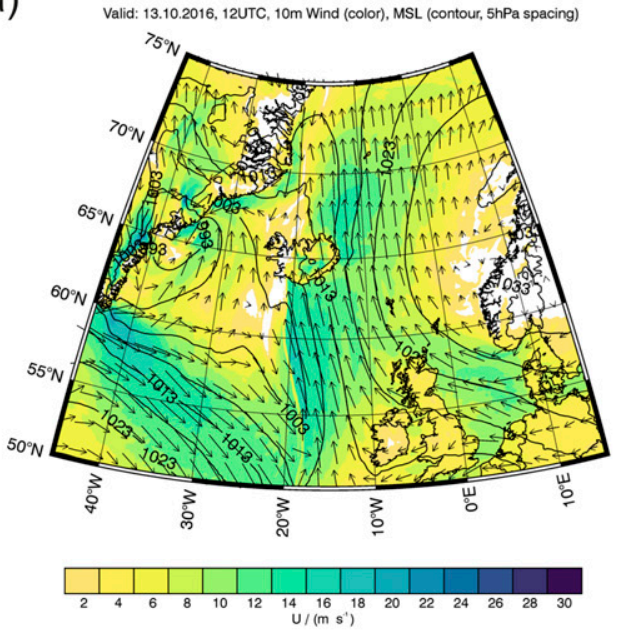

c)

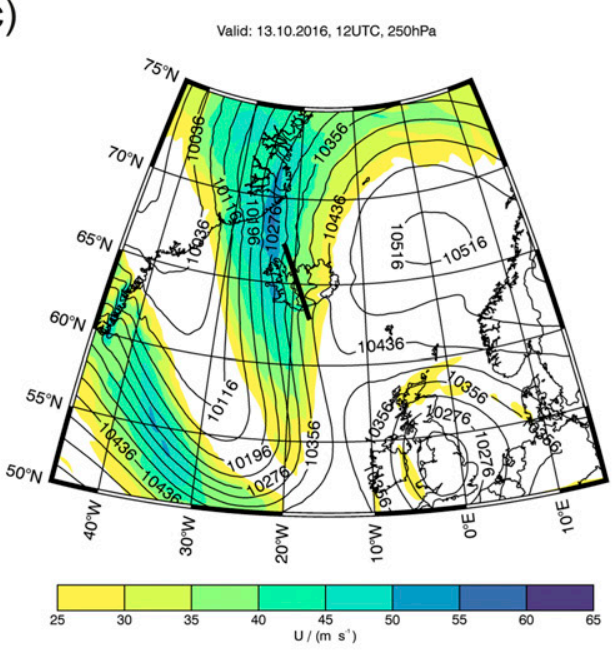

e)

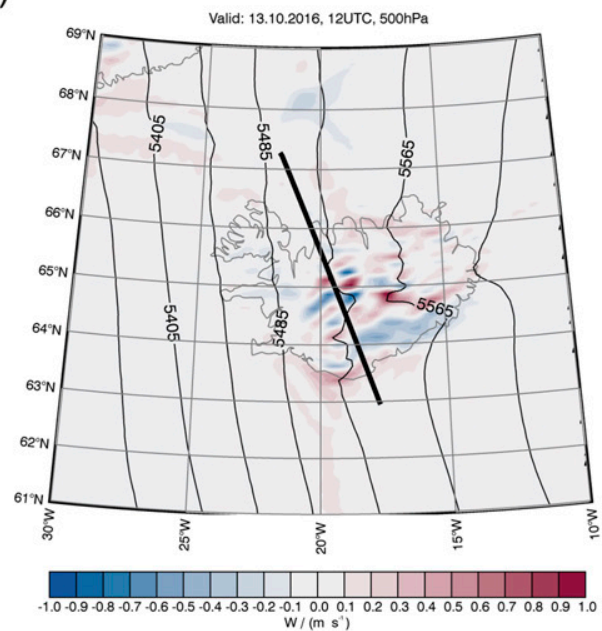

b)

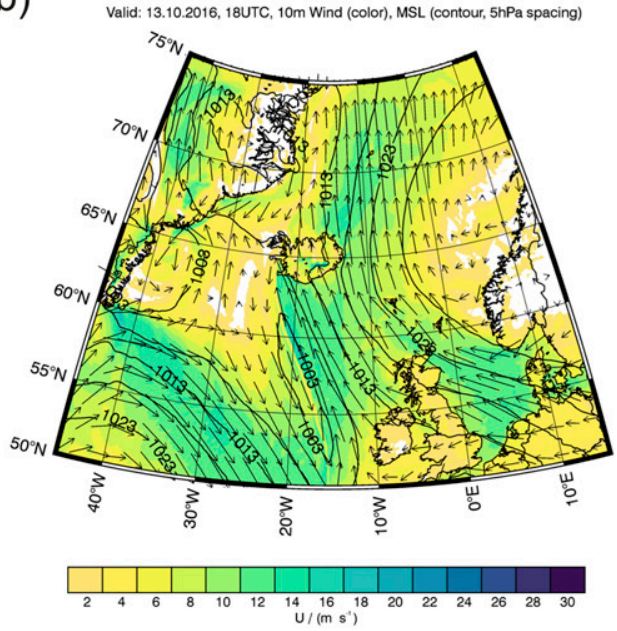

d)

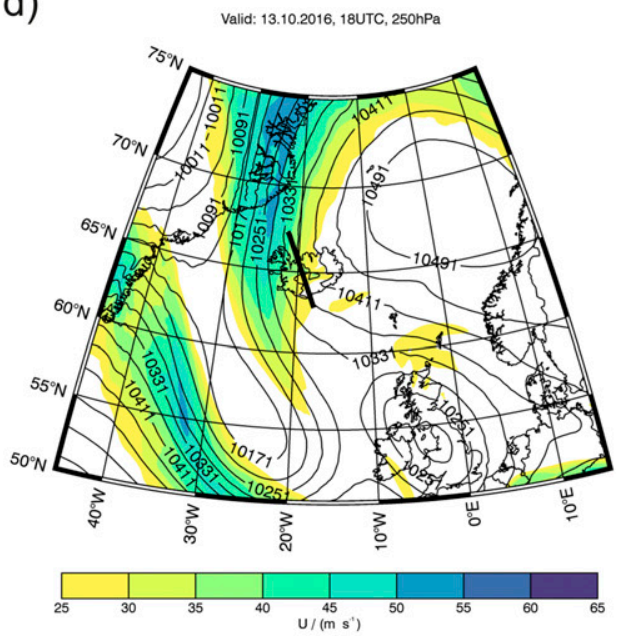

f)

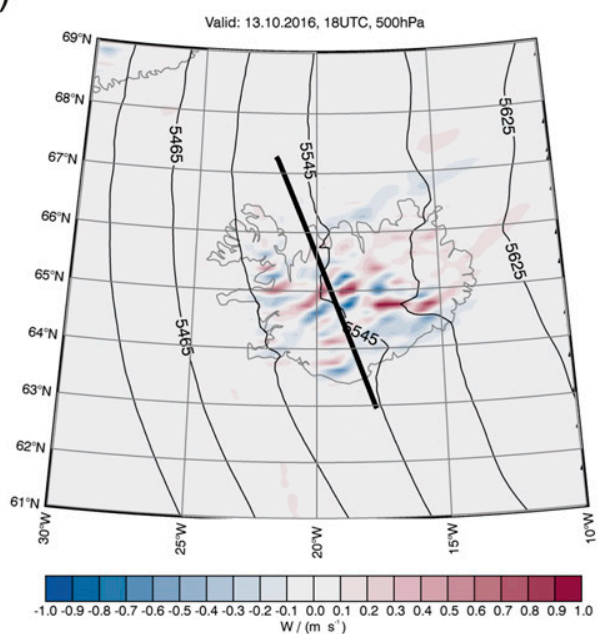

FIG. 3. Horizontal wind speed at (a),(b) $10 \mathrm{~m}$ and (c),(d) $250 \mathrm{hPa}$, and (e),(f) vertical wind speed at $500 \mathrm{hPa}$ as simulated by ECMWF IFS operational analysis for (a),(c),(e) 1200 UTC and (b),(d),(f) 1800 UTC. Thin black lines are the mean sea level pressure in (a),(b) and (c)-(f) show the geopotential, respectively. Black arrows in (a),(b) show wind speed and direction. The thick black line in (c)-(f) shows the flight-track of HALO. 
a)

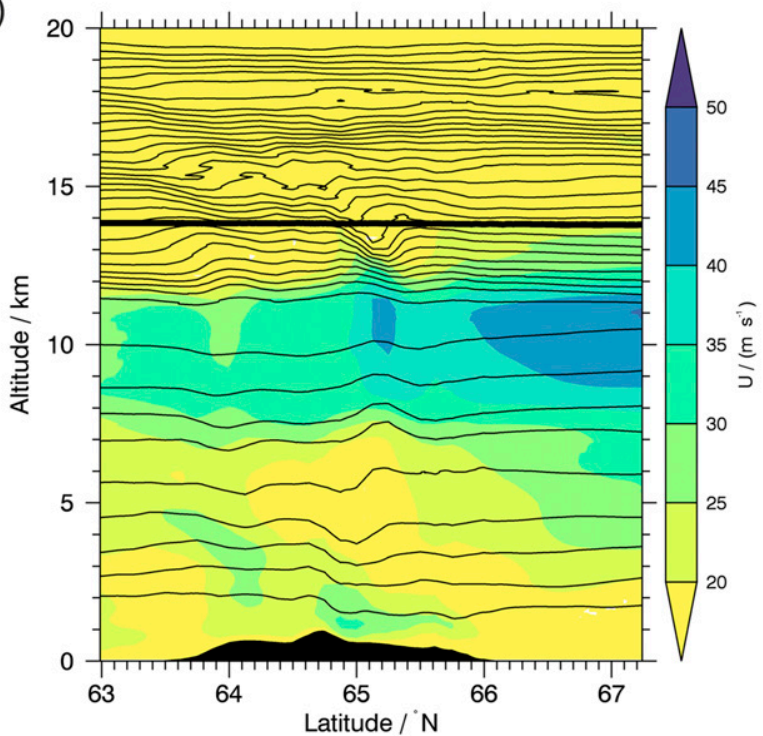

b)

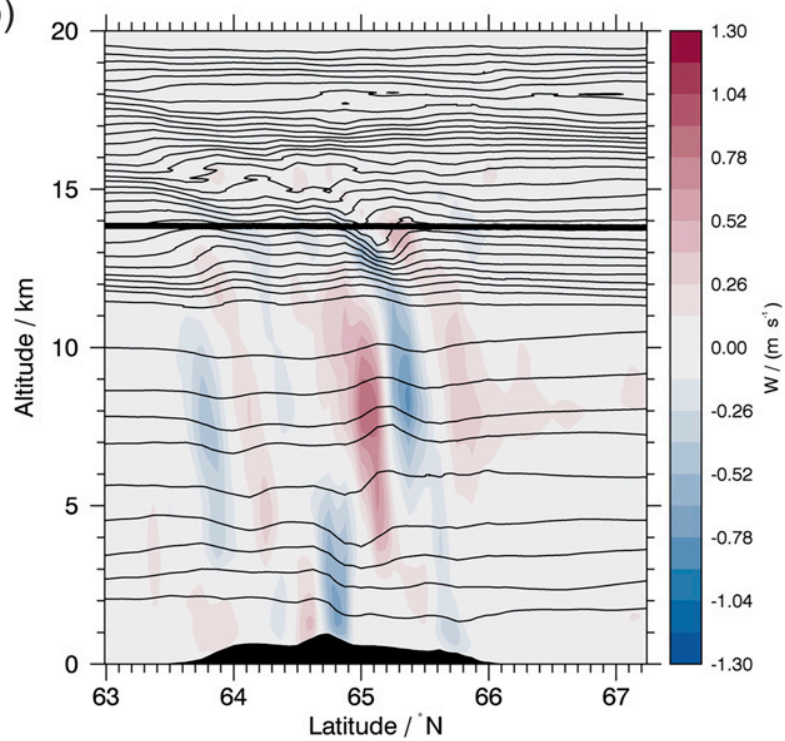

FIG. 4. Vertical profiles of (a) horizontal wind speed and (b) vertical wind speed along the flight track. Thin black lines are isentropes with a spacing of $5 \mathrm{~K}$ and the thick black line shows the flight altitude of HALO, respectively. ECMWF IFS data are interpolated spatially and temporally to the flight track.

Throughout the troposphere, the magnitude of the horizontal wind speeds was mostly $\geq 15 \mathrm{~m} \mathrm{~s}^{-1}$ (see Figs. 4a and 5b ) and almost no directional shear was present due to the alignment of the two jets. In this situation vertical propagation of MWs is generally supported by the background horizontal wind profile as their ground-based phase speed is equal to zero and, therefore, no critical layer can attenuate propagating MWs in the troposphere and near the tropopause by nonlinear processes. These MWs are visible in the vertical wind speed as stationary, coherent structures of up- and downdrafts with amplitudes of about $1 \mathrm{~m} \mathrm{~s}^{-1}$ (Figs. 3e,f), especially, in the area of Langjökull and Hofsjökull. A cross section along the flight track reveals that these MWs are able to propagate up to the tropopause region at an altitude of about $11.5 \mathrm{~km}$ (Fig. 4b).

Above the tropopause, in the lower stratosphere, the horizontal wind speed decreases by about $10 \mathrm{~m} \mathrm{~s}^{-1} \mathrm{~km}^{-1}$ to values smaller than $10 \mathrm{~m} \mathrm{~s}^{-1}$ (Fig. 5b). These small horizontal winds increase the potential for MW breaking due to convective instability as the magnitude of the wave-induced wind perturbations become comparable to the background wind. Indeed, steepening isentropes in the ECMWF forecasts indicate the onset of convective instabilities due to breaking mountain waves in the lower stratosphere where HALO's flight track was located. Consequently, amplitudes in the vertical wind speed decrease by about $0.65 \mathrm{~m} \mathrm{~s}^{-1}$ in this region characterized by the strong negative vertical shear in the horizontal wind (Fig. 5b). Further upward, the forecasts suggest that all MWs are attenuated and, therefore, no significant amplitudes are present in the vertical wind field. This preliminary MW analysis is based on the results of the hydrostatic IFS operational analyses and therefore cannot resolve convective instabilities or any other nonhydrostatic effect on the small-scale vertical wind. However, the hydrostatic response of vertically propagating MWs and the potential of MW breaking is a robust feature of the IFS data around this time.

The vertical profile of the Scorer parameter $l$ upstream of Iceland $\left(63.14^{\circ} \mathrm{N},-17.84^{\circ} \mathrm{E}\right)$ suggests that MWs with a horizontal wavelength $\left(\lambda_{h}\right)$ larger than about $25 \mathrm{~km}$ are freely propagating through the troposphere into the lower stratosphere. Furthermore, MW modes with $7 \lesssim \lambda_{h} \lesssim 20 \mathrm{~km}$ reach their turning points $(k \sim l)$ at an altitude of $12 \mathrm{~km}$ where they are reflected downward. MWs with $\lambda_{h} \lesssim 6 \mathrm{~km}$ are evanescent in the troposphere and should not reach the tropopause level. Above Iceland at the location of the turbulence event $\left(64.97^{\circ} \mathrm{N},-19.40^{\circ} \mathrm{E}\right)$, the Scorer profile is similar to the upstream profile except for the depth of the trapping layer. Here, this layer is thinner by $3 \mathrm{~km}$ covering an altitude range from 7 to $12 \mathrm{~km}$ and consequently MWs with $11 \lesssim \lambda_{h} \lesssim 20 \mathrm{~km}$ are trapped.

\section{b. Lidar and radar measurements}

Downward looking airborne lidar and radar measurements are used to further classify ambient atmospheric conditions during HALO's overpass across Iceland (Fig. 6). Both measurements suggest that south of $65^{\circ} \mathrm{N}$ 
a)

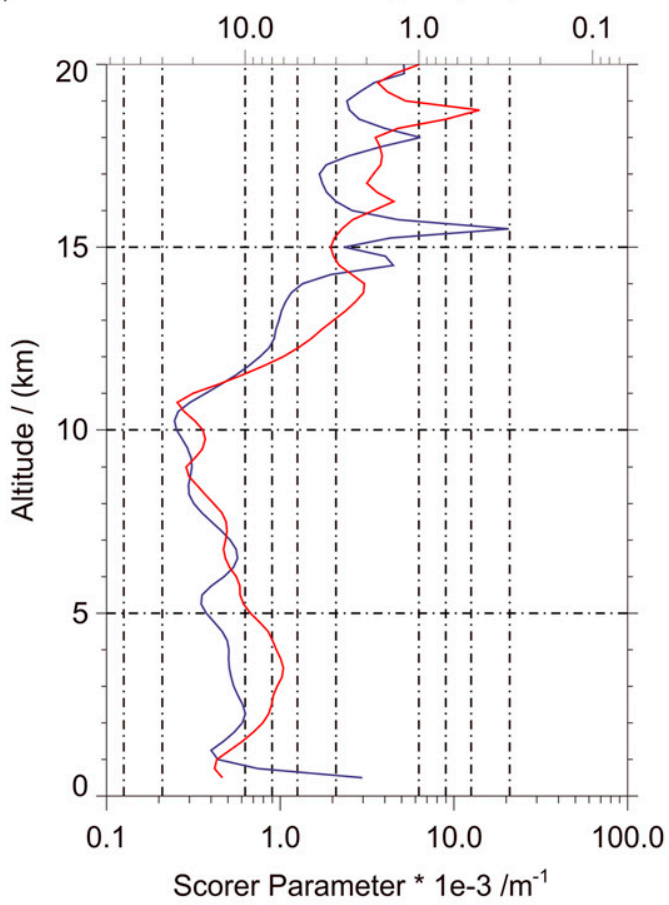

b)

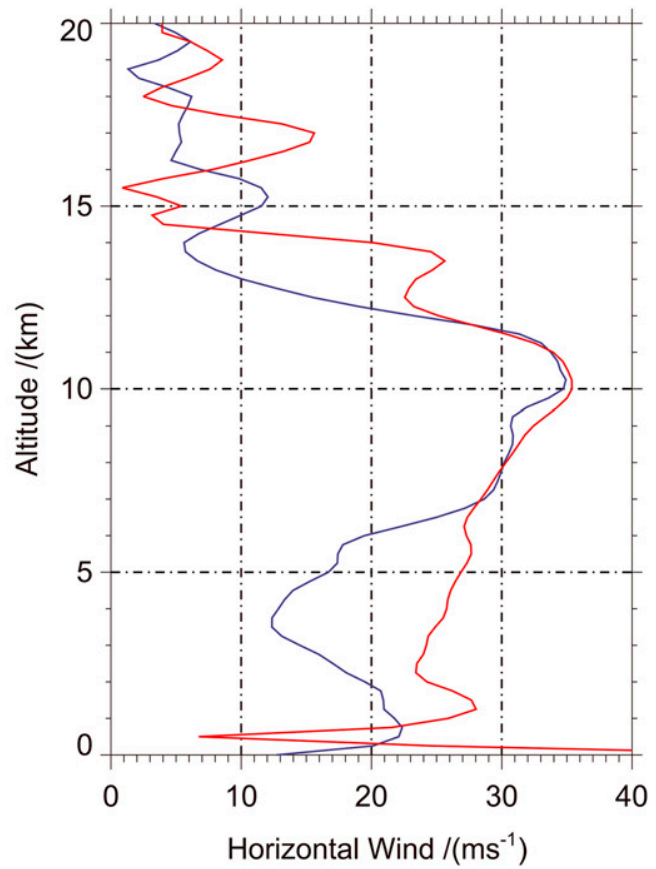

FIG. 5. (a) Vertical profile of the Scorer parameter and (b) horizontal wind speed at the upstream location $\left(63.14^{\circ} \mathrm{N},-17.84^{\circ} \mathrm{E}\right.$, red line) and the location of the turbulence encounter (blue line). All profiles are based on ECMWF IFS operational analyses at 1200 UTC.

clouds prevailed in the troposphere with a cloud top height of about $7.5 \mathrm{~km}$ at maximum. Radar measurements further indicate that rainfall was present with decreasing intensity toward north (Fig. 6b).

North of $65^{\circ} \mathrm{N}$ wavelike structures are superimposed on the signals of both, lidar and radar at an altitude ranging from 5 to $12 \mathrm{~km}$. In the troposphere radar measurements suggest that their horizontal wavelength is about $20 \mathrm{~km}$ and the amplitudes increase with altitude from approximately $700 \mathrm{~m}$ to $1 \mathrm{~km}$. The upstream tilt (see purple lines in Fig. 6b) revealed by the radar measurements suggests that these waves are vertically propagating. Further upward, the lidar backscatter shows a larger-scale wave structure that extends from $65^{\circ} \mathrm{N}$ to about $65.5^{\circ} \mathrm{N}$ at an altitude of about $10.5 \mathrm{~km}$. Downstream this wave structure horizontal wavelengths decrease to approximately $20 \mathrm{~km}$. Above the tropopause (at about $12 \mathrm{~km}$ ) from $65^{\circ}$ to $65.2^{\circ} \mathrm{N}$, the lidar backscatter signal is superimposed by smallscale wavelike structures with a horizontal wavelength of about $3.5 \mathrm{~km}$. According to the Scorer parameter analysis, MWs of that scale are evanescent in the troposphere. Therefore, their source can be attributed to local processes as, for example, MW breaking. However, as the Scorer parameter analysis is based on IFS operational analysis the observed waves can also be produced by processes not resolved by the IFS.

\section{Analysis of aircraft in situ measurements}

To get an overview on the structure of the flow field along the flight track, MW fluxes as well as turbulence parameters derived from $10 \mathrm{~Hz}$ HALO in situ measurements are analyzed. Furthermore, this dataset is combined with $1 \mathrm{~Hz}$ French Falcon in situ measurements to additionally analyze the vertical extent and distribution of marked features of the flow field.

HALO in situ observations reveal large peak-to-peak amplitudes in all presented meteorological parameters at $\sim 65^{\circ} \mathrm{N}$, the location of the turbulence encounter (see Fig. 7). Especially, in the vertical wind speed large values up to $7.6 \mathrm{~m} \mathrm{~s}^{-1}$ are detected. These pronounced amplitudes possibly led to the encountered altitude changes of about $50 \mathrm{~m}$ within about $15 \mathrm{~s}$ of the research aircraft HALO in this area. Additionally, in this area both horizontal wind speed components decrease to values of about $0 \mathrm{~m} \mathrm{~s}^{-1}$. Small-scale structures are superimposed on all presented meteorological parameters in this region. This might be due to turbulence induced by nonlinear processes as, for example, breaking mountain waves. In general, both the horizontal wind 
a)

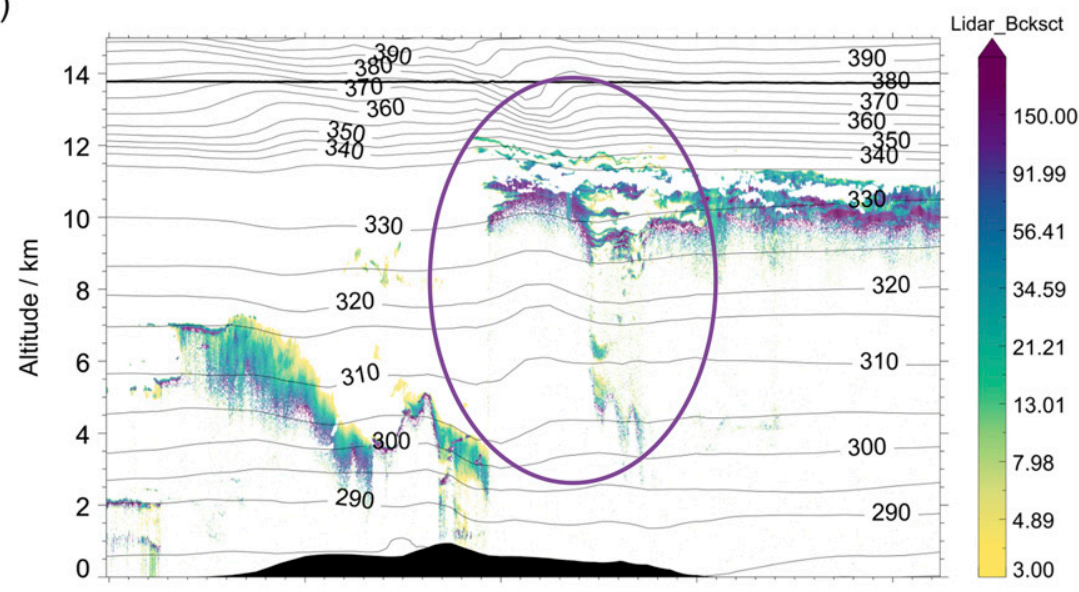

b)

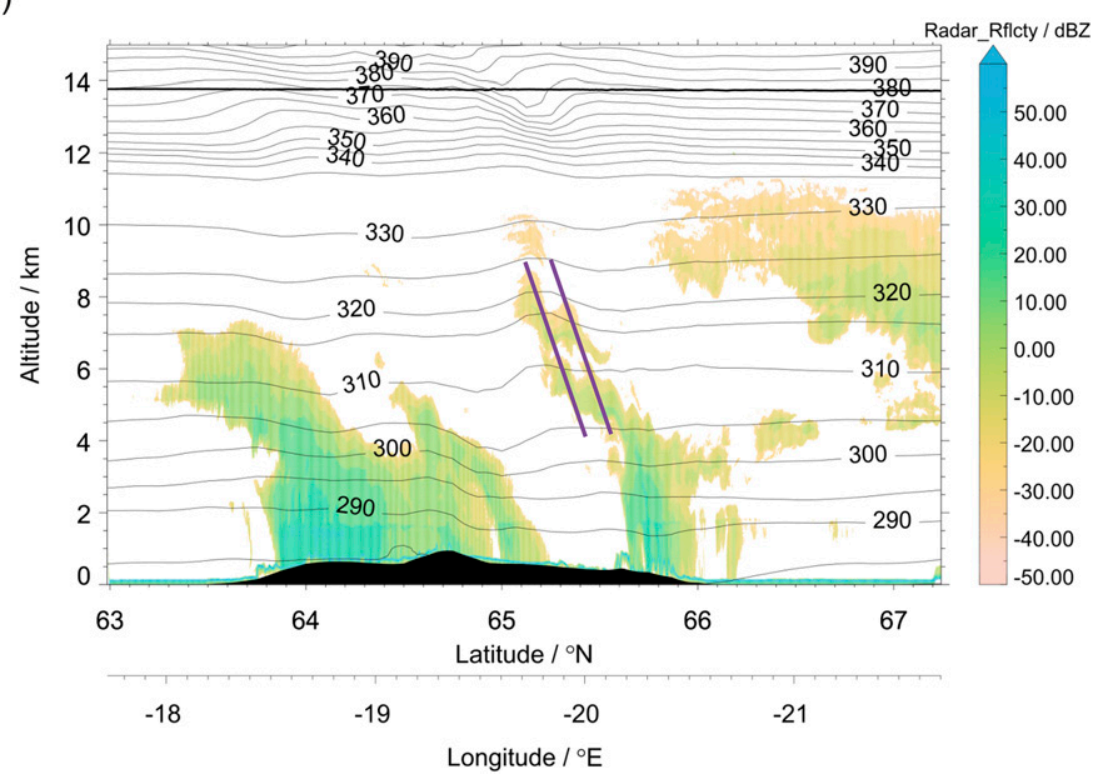

FIG. 6. (a) Lidar backscatter ratio measured with the downward looking airborne lidar WALES and (b) radar reflectivity measured with the coaligned cloud radar HAMP MIRA along the flight track of HALO. Isentropes are taken from ECMWF IFS operational analyses interpolated spatially and temporally to the flight track.

and the potential temperature measurements are characterized by larger-scale wave patterns with a horizontal wavelength of about $60 \mathrm{~km}$ in contrast to the vertical wind, which is dominated by small-scale waves.

North of this area starting at about $65.8^{\circ} \mathrm{N}$, smooth wave patterns without superimposed small-scale structures dominate in all parameters. While peak-to-peak amplitudes in the horizontal wind speed components become small with values up to about $5 \mathrm{~m} \mathrm{~s}^{-1}$, they are pronounced in the vertical wind and in the potential temperature with about $3 \mathrm{~m} \mathrm{~s}^{-1}$ at maximum and approximately $4 \mathrm{~K}$, respectively. In this region no clear $90^{\circ}$ phase shift between vertical wind and potential temperature can be detected that would indicate vertically propagating linear gravity waves (GWs).

South of Iceland (upstream), between about $63^{\circ}$ and $63.7^{\circ} \mathrm{N}$, no pronounced amplitudes are detected in all presented parameters. Also, in the vertical wind speed, the amplitudes decrease to values smaller than about $0.5 \mathrm{~m} \mathrm{~s}^{-1}$. Consequently, no significant wave or smallscale structures can be found suggesting calm atmospheric flight conditions as reported by the pilots.

Comparison of HALO observations to the French Falcon in situ measurements reveals similar patterns in all meteorological parameters along the respective flight tracks (see Fig. 7). In the area of the turbulence 

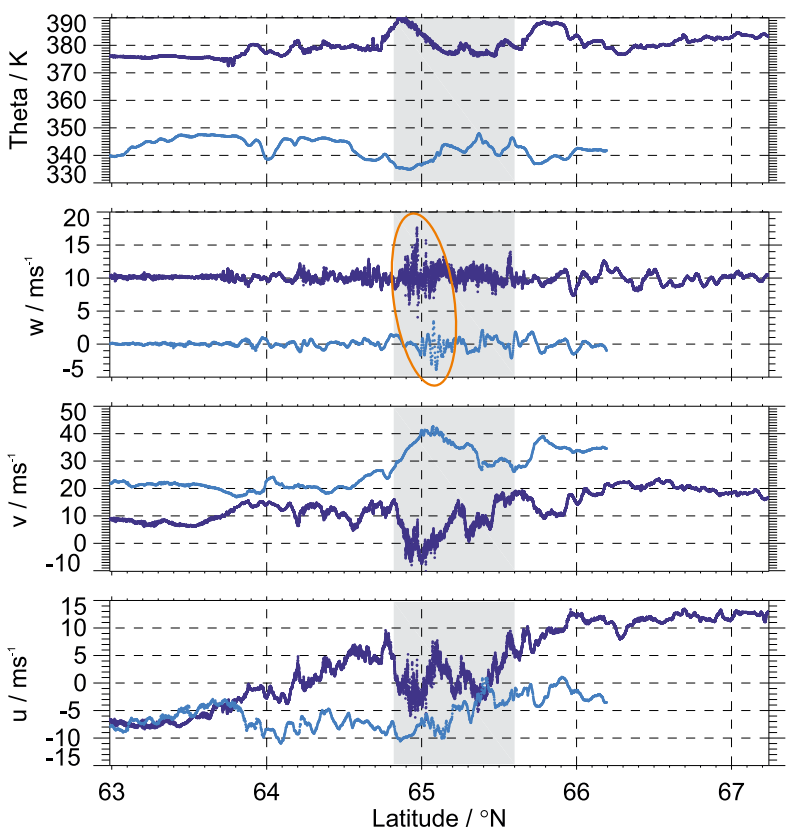

FIG. 7. HALO $10 \mathrm{~Hz}$ in situ measurements (dark blue lines) of (top) potential temperature, (second panel from top) vertical wind speed, and (bottom two panels) meridional and zonal wind speed. The light blue lines refer to French Falcon $1 \mathrm{~Hz}$ in situ measurements. HALO measurements are located at $13.8 \mathrm{~km}$ and French Falcon observations at $11.8 \mathrm{~km}$, respectively. Orange ellipse connects turbulent structures of the two measurements. The gray shading refers to the region of the turbulence encounter that coincides with the time where the autothrottle system of HALO was deactivated. For better comparison the vertical wind measurement of HALO is shifted by $10 \mathrm{~m} \mathrm{~s}^{-1}$ in the second panel from top.

encounter both measurements show enhanced vertical wind speeds where the French Falcon-observed vertical wind speeds are with a maximum of about $3.4 \mathrm{~m} \mathrm{~s}^{-1}$ only approximately half of the HALO-observed vertical wind maximum. Connecting the maximum vertical wind speeds of the two measurements reveals an upstream vertical tilt of the turbulent region (see ellipse in Fig. 7, flight altitudes of HALO and the French Falcon are 13.8 and $11.8 \mathrm{~km}$, respectively). At this location where the maximum vertical wind is encountered, the meridional wind speed observed by the French Falcon increases to about $40 \mathrm{~m} \mathrm{~s}^{-1}$. This suggests that a negative vertical shear of the horizontal wind was present in this area.

\section{a. Analysis of mountain waves in the lower stratosphere}

To determine the linearity of the observed MWs, the Eliassen-Palm relation is tested. Figure 8 shows the result of this analysis where an almost perfectly linear wave signature can be seen when both curves match each other closely. Deviations can have different reasons as discussed below.
Analysis of the fluxes integrated over the complete flight leg suggests upward-propagating MWs with a positive $\mathrm{EF}_{z}$ of $1.26 \mathrm{~W} \mathrm{~m}^{-2}$ and $-\mathrm{UMF}$ of $2.07 \mathrm{~W} \mathrm{~m}^{-2}$ (not shown). However, these values are low and the magnitude of $\mathrm{EF}_{z}$ is reduced by $40 \%$ compared to $-\mathrm{UMF}$, indicating that nonlinear processes are also present. Note that these fluxes include all possible scales.

Analyzing the Eliassen-Palm fluxes derived from HALO in situ measurements reveals a complicated situation regarding linear MW properties along the flight track (see Fig. 8). The scale-separated energy fluxes upstream of the turbulence encounter detect relatively small large-scale energy fluxes (see Fig. 8a and blue line in Fig. 8c). However, these increase gradually toward north until they reach values of up to about $2 \mathrm{~W} \mathrm{~m}^{-2}$ for the energy flux in the lee of Myrdalsjökull. Starting at about $64^{\circ} \mathrm{N}$ the energy fluxes $\mathrm{EF}_{z}$ and UMF show some alignment. Thus the observations suggest linearly upward-propagating MWs in this region (see Figs. 8a,c). At turbulent scales (see Fig. $8 \mathrm{~b}$ and orange line in Fig. 8c), no pronounced values were observed in the energy and heat fluxes upstream of the turbulence encounter.

At the location of the turbulence event (gray shaded area in Fig. 8) the energy fluxes show pronounced peaks. In this region, the linear relationship $\mathrm{EF}_{z}$ and UMF breaks down completely and even an anticorrelation of the two fluxes evolves (see Figs. 8a,b). Together with the finding of the differing leg-integrated fluxes, the structure of these fluxes suggests the presence of nonlinear processes. In this region the large-scale fluxes of the $\mathrm{EF}_{z}$ increase up to $4 \mathrm{~W} \mathrm{~m}^{-2}$ and about $6 \mathrm{~W} \mathrm{~m}^{-2}$ of UMF, respectively. At turbulent scales, the values of $\mathrm{EF}_{z}$ decrease from about $+1.5 \mathrm{~W} \mathrm{~m}^{-2}$ to about $-6 \mathrm{~W} \mathrm{~m}^{-2}$ and for UMF from approximately $+1 \mathrm{~W} \mathrm{~m}^{-2}$ to about $-3.5 \mathrm{~W} \mathrm{~m}^{-2}$, respectively. Furthermore, the vertical heat flux at turbulence scale peaks up to about $10 \mathrm{~W} \mathrm{~m}^{-2}$ around $65^{\circ} \mathrm{N}$ (Fig. 8c).

Downstream of the turbulence encounter (north of $65.6^{\circ} \mathrm{N}$ ), the fluxes generally decrease to smaller values. In particular at turbulent scales no pronounced energy and heat fluxes were observed in this area (see Fig. 8b and orange line in Fig. 8c). However, around $66.2^{\circ} \mathrm{N}$, enhanced values of large-scale $\mathrm{EF}_{z}$ were detected (see Fig. 8a). Here, the large-scale $\mathrm{EF}_{z}$ increases up to about $8 \mathrm{~W} \mathrm{~m}^{-2}$. As $\mathrm{EF}_{z}$ and UMF are not aligned in this area these observations indicate the presence of nonlinear MWs.

The cospectra analysis of $\mathrm{EF}_{z}$ and $\mathrm{MF}_{y}$ shows that locally the majority of significantly energy-containing fluxes have horizontal wavelengths $\left(\lambda_{h}\right)$ less than $10 \mathrm{~km}$ (see Figs. 9a,b). These are located at and north of the region of 
a)

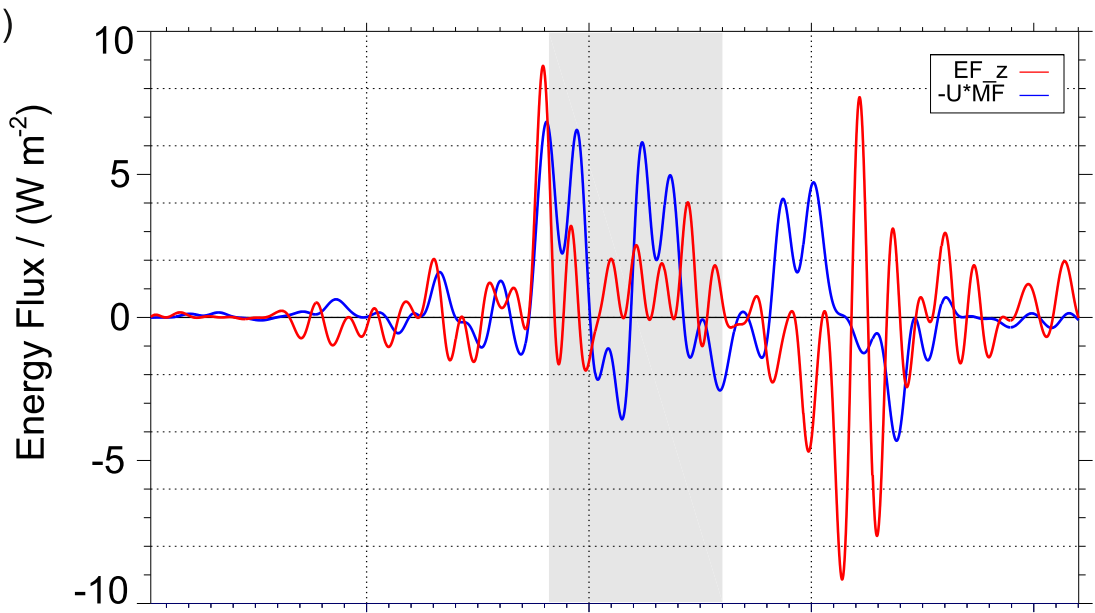

b)
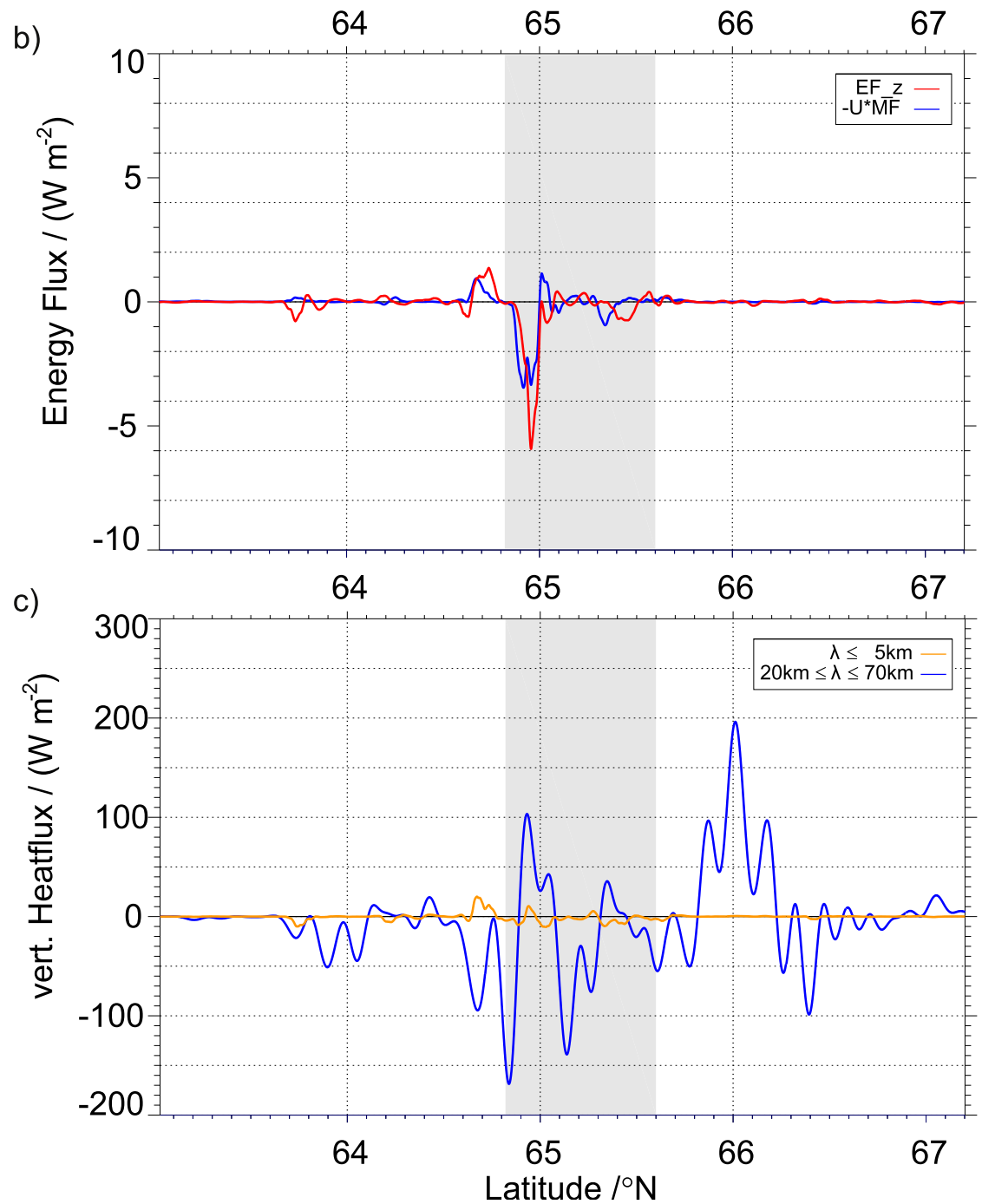

FIG. 8. (a),(b) Scale separated vertical energy flux $\left(\mathrm{EF}_{z}\right.$, red) and energy flux derived from horizontal momentum fluxes (UMF, blue) along the complete flight leg. (a) Fluxes derived for $20 \leq \lambda_{h} \leq 70 \mathrm{~km}$ and (b) fluxes related to the turbulent scale $\left(\lambda_{h} \leq 5 \mathrm{~km}\right)$. (c) Scale-separated vertical heat flux along the flight track. Dark blue line shows the heat flux for the propagating MW scale (20 to $70 \mathrm{~km}$ ) and the orange line refers to the heat flux of the turbulent scales, respectively. 
a)

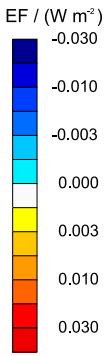

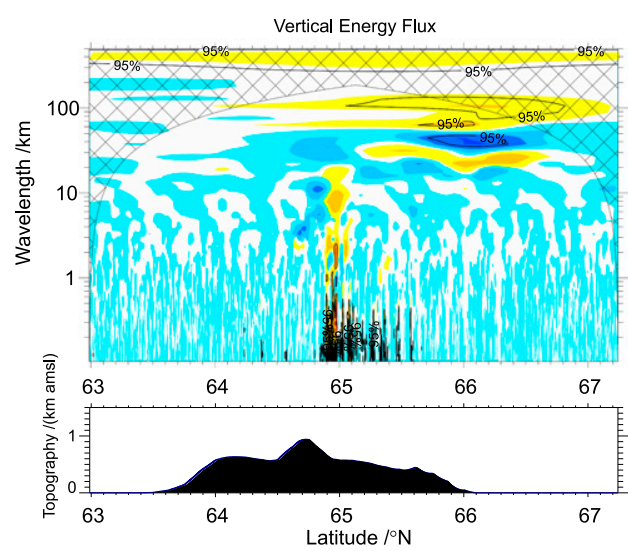

b)

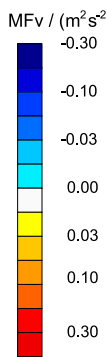

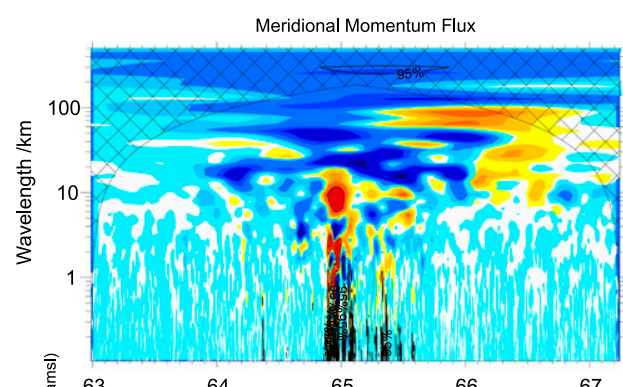

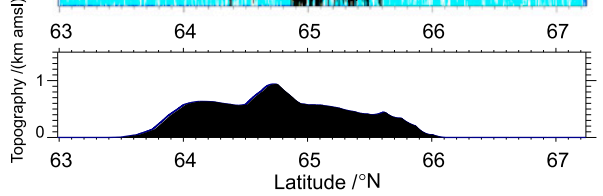

c)
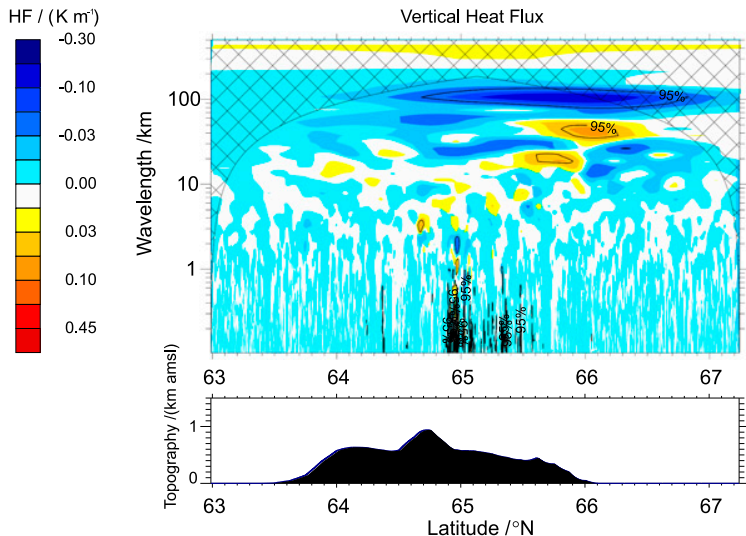

FIG. 9. Cospectra of (a) vertical energy flux $\left(\mathrm{EF}_{z}\right)$, (b) meridional momentum flux $\left(\mathrm{MF}_{y}\right)$, and (c) vertical heat flux (VHF).

the turbulence encounter. Here, we particularly show the meridional component of the momentum flux as the horizontal wind direction was mainly meridionally oriented. These wave scales can be attributed to the small-scale and turbulent range as defined in Smith et al. (2016). Taking into account the Scorer parameter, these small-scale signatures cannot be related to small-scale MWs excited at the surface but rather to breaking MWs or secondary GWs.

\section{b. Turbulence analysis}

Figure 10a shows the along-track profiles of TKE calculated from in situ wind measurements on different subleg lengths (see also section 2). The presented subleg lengths range from 4 to $16 \mathrm{~km}$. The magnitude of TKE decreases with decreasing subleg length, as expected. Turbulent scales affecting aircraft are favored in the range from about $300 \mathrm{~m}$ to $1 \mathrm{~km}$ (MacCready 1964; Vinnichenko et al. 1980; Hoblit 1988; Sharman et al. 2014). As we are mainly interested in these scales, we analyze the turbulence on the $4 \mathrm{~km}$ sublegs in the following.

Here, the largest variance in the wind speed was observed at $64.9^{\circ} \mathrm{N}$, the location of the turbulence encounter. In this area the TKE is enhanced by a factor of about 10 compared to the rest of the leg. Values increase to $\approx 11 \mathrm{~m}^{2} \mathrm{~s}^{-2}$ in the maximum in this region suggesting pronounced atmospheric turbulence. Enhanced TKE magnitudes larger than $1 \mathrm{~m}^{2} \mathrm{~s}^{-2}$ are present between about $64.8^{\circ}$ to $65.7^{\circ} \mathrm{N}$. South and north of the location of the turbulence encounter, almost no TKE is contained in the $4 \mathrm{~km}$ sublegs. TKE values in these regions are smaller than the nominal threshold value of 0.6 used by Strauss et al. (2015), indicating calm atmospheric flight conditions for HALO.

As already suggested by the TKE analysis, also the distribution of EDR along the flight track indicates that the turbulence encounter was a localized event where the maximum turbulence covers a distance of about $20 \mathrm{~km}$ (Fig. 10b). While south of $64.8^{\circ} \mathrm{N}$ at maximum light turbulence was detected, EDR increases abruptly by a factor of $\sim 3$ within about $0.1^{\circ}$ latitude in all three wind components. Here, moderateto-severe EDR values are present at about $65^{\circ} \mathrm{N}$ with a maximum of $0.39 \mathrm{~m}^{2 / 3} \mathrm{~s}^{-1}$. North of this turbulent area, EDR decreases gradually until calm atmospheric flight conditions prevail again north of $65.7^{\circ} \mathrm{N}$.

Individual $\mathrm{EDR}_{i}$ values scatter around the geometric mean $\overline{\mathrm{EDR}}$, indicating mostly anisotropic turbulent 
a)

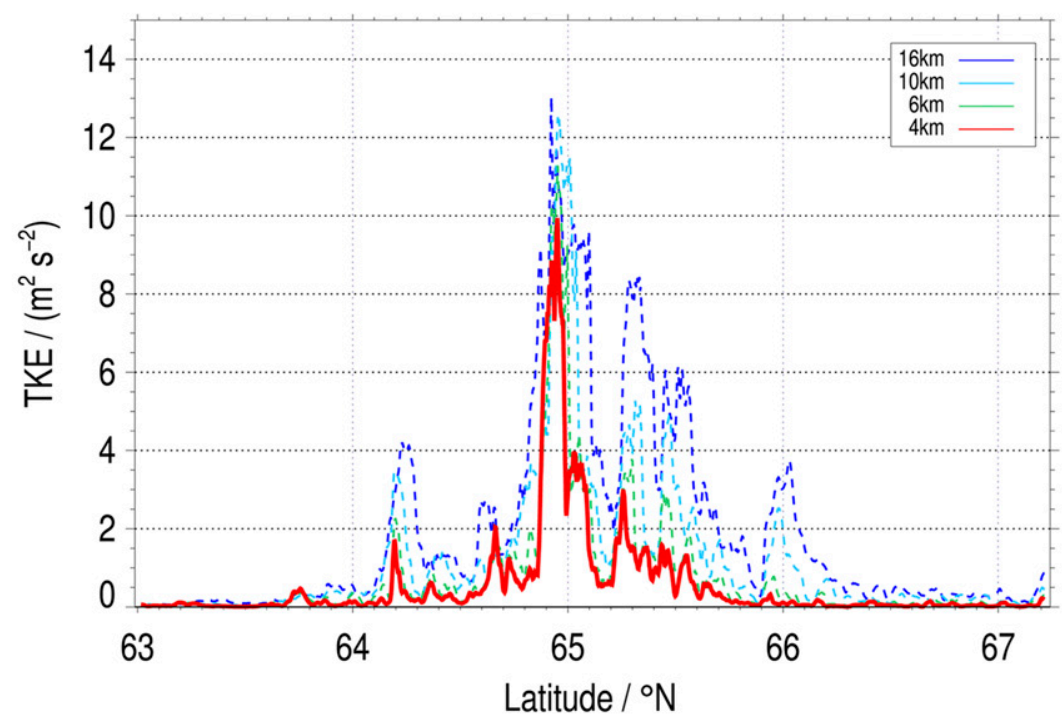

b)

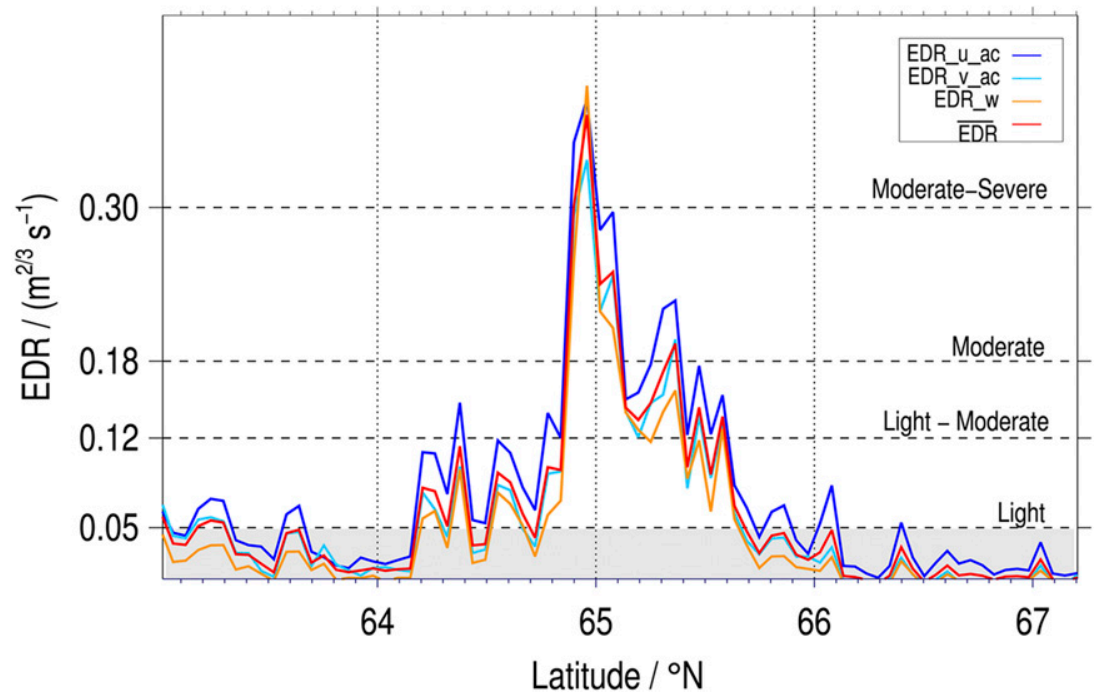

FIG. 10. (a) Turbulent kinetic energy (TKE) derived from different subleg lengths. (b) Energy dissipation rate (EDR) for all wind components in an aircraft related coordinate system and the geometric mean $\overline{\mathrm{EDR}}$ calculated from all wind components.

conditions due to, for example, the high thermal stratification in the stratosphere. In the area of the turbulence encounter conditions are more isotropic as $\mathrm{EDR}_{u_{\mathrm{ac}}}$ and $\mathrm{EDR}_{w}$ are almost equal.

In this study we cannot show EDR values based on the French Falcon in situ observations as with $1 \mathrm{~Hz}$ their resolution is too coarse.

\section{ECMWF and GTG predictions of the event}

For the comparison of the in situ measurements and the ECMWF IFS forecasts, the in situ measurements are averaged over a distance of about $25 \mathrm{~km}$. This was done to analyze how well the background conditions are reproduced by the ECMWF IFS.

Generally, the spatially and temporally interpolated ECMWF IFS forecasts agree very well with the averaged in situ measurements and reproduce the measured mesoscale structures (see Figs. 11 and 12 ). Compared to the HALO in situ measurements (Fig. 11) the difference in potential temperature is $-1.99 \mathrm{~K}$ on average and $1.48 \mathrm{~m} \mathrm{~s}^{-1}$ in the zonal wind component (see also Table 1). While the ECMWF IFS reproduces the observed French Falcon (Fig. 12) potential temperature 

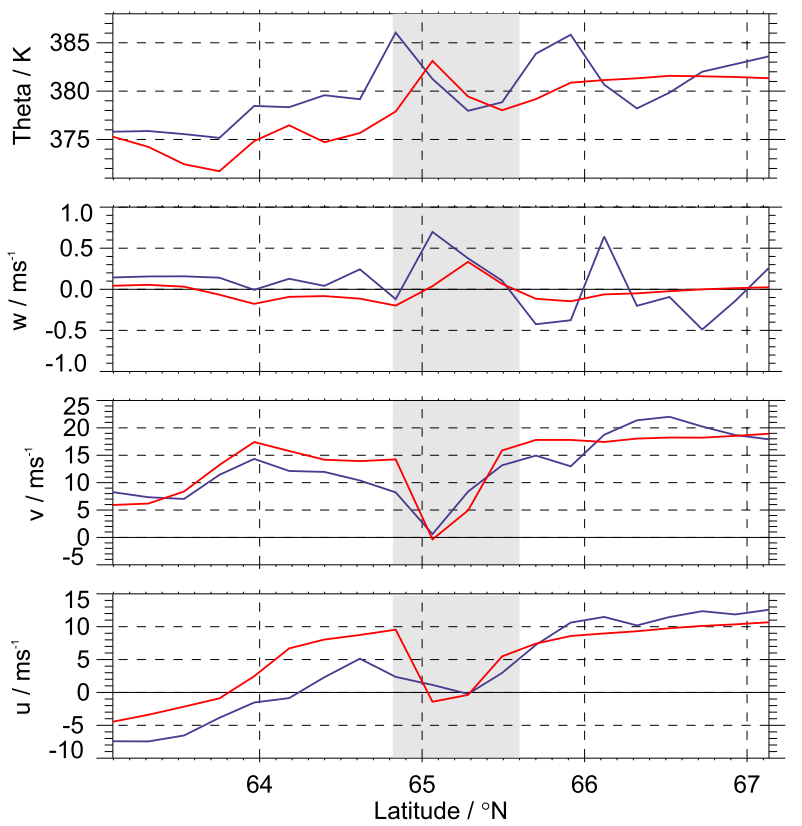

FIG. 11. Averaged HALO in situ measurements (blue lines) of (top) potential temperature, (second panel from top) vertical wind speed, and (bottom two panels) meridional and zonal wind speed. The red lines refer to ECMWF IFS forecasts interpolated spatially and temporally to the flight track. The gray shading highlights the region of the turbulence encounter.

almost perfectly, again the differences increase for the horizontal wind components (see also Table 2). Here, the magnitude of the absolute difference in meridional wind is with $-2.10 \mathrm{~m} \mathrm{~s}^{-1}$ on average larger than for the zonal wind with $1.55 \mathrm{~m} \mathrm{~s}^{-1}$. Overall, the agreement between ECMWF IFS forecasts and the French Falcon is better than the comparison to HALO. This might be expected as the French Falcon was flying in a more undisturbed environment.

In the area of the turbulence encounter, the large gradients in the potential temperature, meridional and zonal wind are well reproduced. However, the location of the potential temperature and zonal wind gradients is predicted farther to the north by about $0.15^{\circ}$ compared to the HALO in situ measurements. Additionally, the decrease of the zonal wind speed is forecasted too large by up to about $4 \mathrm{~m} \mathrm{~s}^{-1}$, while the potential temperature increase is smaller by about $3 \mathrm{~K}$ in the forecast. In contrast to the comparison to HALO observations the increase of the forecasted zonal wind speed is located farther to the south compared to the French Falcon measurements and is about $3 \mathrm{~m} \mathrm{~s}^{-1}$ too small.

To forecast aviation turbulence, the GTG combines CAT and MWT predictions by taking the maximum value at a time of either diagnostic. Analysis of this combination reveals that the magnitude and location of
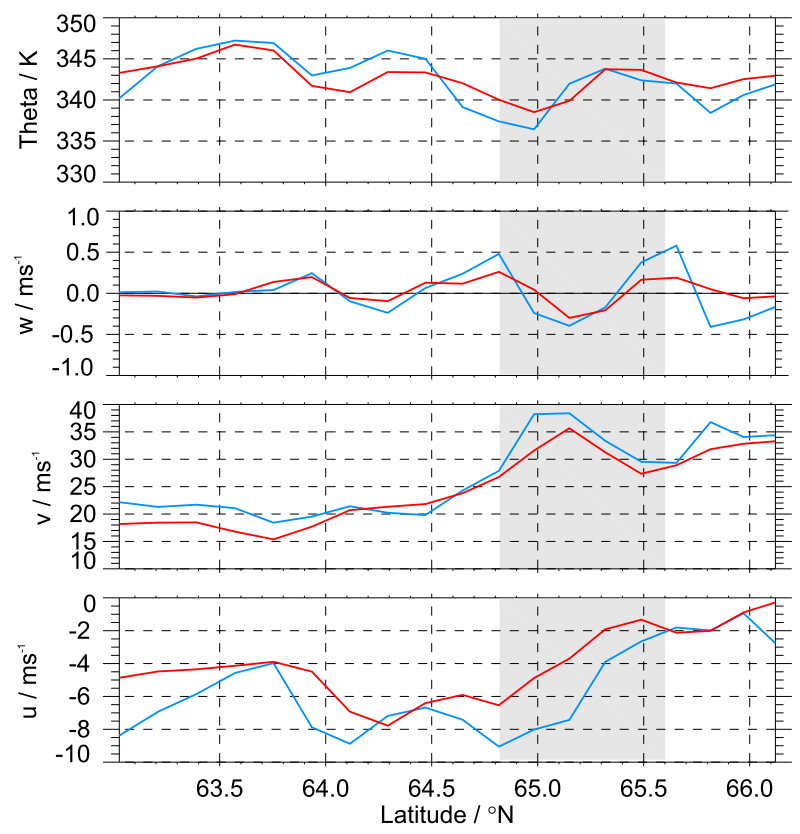

FIG. 12. Averaged French Falcon in situ measurements (blue lines) of (top) potential temperature, (second panel from top) vertical wind speed, and (bottom two panels) meridional and zonal wind speed. The red lines refer to ECMWF IFS forecasts interpolated spatially and temporally to the flight track. The gray shading highlights the region of the turbulence encounter.

maximum encountered turbulence was forecasted correctly. However, in general the GTG has a clear tendency to overpredict the magnitude of turbulence for most of the flight track (see Fig. 13a). Here, the mean difference between forecasted and measured EDR is about $0.17 \mathrm{~m}^{2 / 3} \mathrm{~s}^{-1}$ (see Fig. 13c). Additionally, the detected turbulent intermittency is not captured in the forecasts.

Comparison of the MWT to the CAT diagnostic (see Fig. 13c) reveals that the correct forecast of the maximum turbulence magnitude is due to the MWT component (proportional to the IFS surface vertical velocity), which consists in this study of the diagnostics MWT2 (proportional to $C_{T}^{2}$ ) and MWT3 (proportional

TABLE 1. Overview on the mean difference between HALO in situ measurements and ECMWF data along the complete leg for the different meteorological parameters and the respective standard deviation.

\begin{tabular}{lc}
\hline \hline & $\begin{array}{c}\text { Mean difference } \\
\text { (ECMWF }- \text { in situ) }\end{array}$ \\
\hline Temperature & $-1.99 \pm 1.65 \mathrm{~K}$ \\
Potential temperature & $-1.83 \pm 2.81 \mathrm{~K}$ \\
Vertical wind & $-0.09 \pm 0.29 \mathrm{~m} \mathrm{~s}^{-1}$ \\
Meridional wind & $0.73 \pm 2.91 \mathrm{~m} \mathrm{~s}^{-1}$ \\
Zonal wind & $1.48 \pm 3.39 \mathrm{~m} \mathrm{~s}^{-1}$ \\
\hline
\end{tabular}


TABLE 2. Overview on the mean difference between French Falcon from SAFIRE in situ measurements and ECMWF data along the complete leg for the different meteorological parameters and the respective standard deviation.

\begin{tabular}{lc}
\hline \hline & $\begin{array}{c}\text { Mean difference } \\
\text { (ECMWF }- \text { in situ) }\end{array}$ \\
\hline Temperature & $-0.10 \pm 1.23 \mathrm{~K}$ \\
Potential temperature & $0.26 \pm 1.97 \mathrm{~K}$ \\
Vertical wind & $0.41 \pm 0.19 \mathrm{~m} \mathrm{~s}^{-1}$ \\
Meridional wind & $-2.10 \pm 2.07 \mathrm{~m} \mathrm{~s}^{-1}$ \\
Zonal wind & $1.55 \pm 1.40 \mathrm{~m} \mathrm{~s}^{-1}$ \\
\hline
\end{tabular}

to the 3D frontogenesis function) (Sharman and Pearson 2017). Interpolation of the GTG data to the flight track (Fig. 13c) shows that the general shape of the MWT diagnostic also approximately follows the measured EDR, yet with values that are mostly larger than the measured EDR. The mean difference between MWT and measured EDR is smaller by about $0.02 \mathrm{~m}^{2 / 3} \mathrm{~s}^{-1}$ compared to the GTG combination.

\section{2D EULAG simulations}

EULAG simulations with a 2D setup are used to study the generation mechanism of the turbulence encountered by HALO (Fig. 14). In this simulation, a hydrostatic MW evolves above the highest elevation of the topography (between $-50 \mathrm{~km}$ to the center of the domain) with a horizontal wavelength of about $50 \mathrm{~km}$ and the maximum amplitude in the vertical wind of $\sim 1 \mathrm{~m} \mathrm{~s}^{-1}$. Due to the strongly decreasing horizontal wind speed together with increasing stability in the stratosphere, phase lines tilt upstream in the lower stratosphere between an altitude of 12.5 and $15 \mathrm{~km}$, which is in concurrence with the results of the analysis of the ECMWF IFS data.

In this region, EULAG simulations suggest the evolution of a pronounced MW breaking region after three simulation hours (Fig. 14). Here, the values of the MW-induced perturbations of the horizontal wind and the magnitude of the background horizontal wind itself are almost equal (not shown). As the direction of the horizontal wind perturbation is opposite to the direction of the background horizontal wind the two wind components cancel each other out and a critical level for MWs evolves. Furthermore, isentropic surfaces steepen and, eventually, overturn during convective instability in this area. Turbulent mixing due to this overturning is reflected by nearly vertical isentropic surfaces suggesting locally neutral stratification. Consequently, small-scale wave structures with amplitudes in the vertical wind of about $6.6 \mathrm{~m} \mathrm{~s}^{-1}$ dominate in a comparable area where HALO encountered the turbulence. As the numerical simulations are $2 \mathrm{D}$ and do not resolve turbulence explicitly, the simulated structures appear at the grid scale (Fig. 14a). The nonoscillatory forwardin-time (NFT) numerics ensures that the model simulations maintain numerical stability. Moreover, the observed downstream shift of the turbulent region found in the French Falcon data at $11.8 \mathrm{~km}$ altitude is reproduced by EULAG.

In accordance with the observations, EULAG simulations reveal that small-scale disturbances are superimposed also on the horizontal wind and the temperature in the MW breaking region (Figs. 14b,d). Additionally, in this region EULAG reproduces in the horizontal wind the deceleration observed by HALO and the acceleration measured by the French Falcon (Fig. 14c). Here, the simulations indicate that these observed changes of the horizontal wind are due to the wave-induced perturbations where the acceleration observed by the French Falcon can be explained with a summation of the wave-induced perturbation and the background horizontal wind due to their similar orientation.

Furthermore, EULAG simulations suggest that the observed large-scale perturbations in horizontal wind speed and temperature at and downstream (up to about $66^{\circ} \mathrm{N}$ ) of the turbulence encounter are related to MW activity. The perturbation of the horizontal wind speed reveals a pattern of accelerated and decelerated regions related to the large-scale hydrostatic MW along the flight track that are also found in the in situ observations of both aircraft. Likewise, large-scale cold and warm anomalies are present in the potential temperature due to the described hydrostatic MWs (Fig. 14b).

\section{Discussion and conclusions}

This case study analyzes the dominant processes involved in the generation of turbulence encountered by HALO on 13 October 2016 during NAWDEX. By using the presented results, the observed turbulence can be attributed to breaking MWs in the lower stratosphere. To our knowledge for the first time, the simultaneous observation of a MW breaking region by two research aircraft at two different altitudes is reported.

In our study, 2D idealized simulations proved to sufficiently reproduce essential features of the in situ measurements as, for example, the horizontal scales and the large amplitudes in the vertical wind speed. Also, Doyle et al. (2000) were able to simulate the upper-level breaking of MWs with 2D nonhydrostatic models. That way, we could attribute the observed turbulence to breaking MWs with these simulations.

Here, a pronounced hydrostatic MW is excited at the mountainous terrain underneath the flight track. 
a)

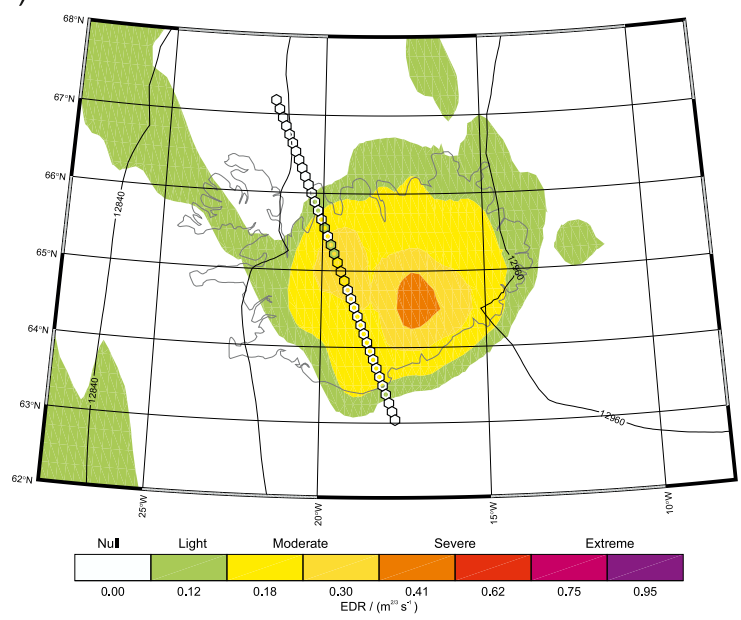

b)

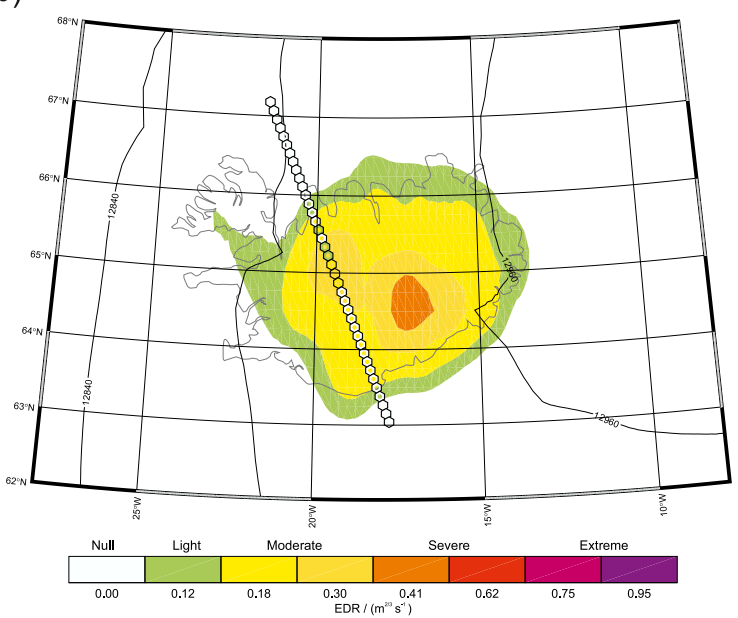

c)

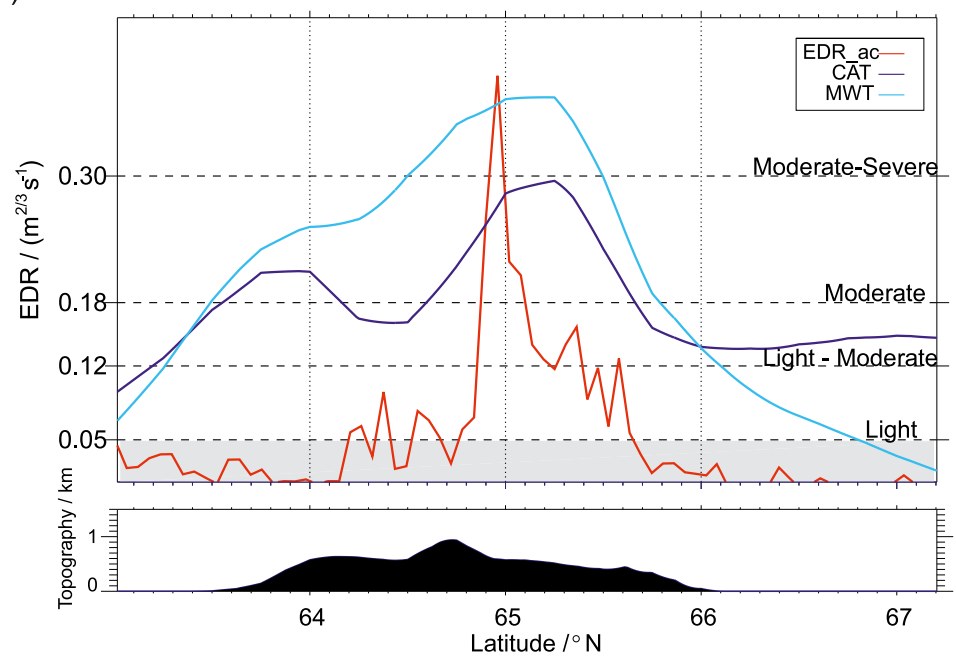

FIG. 13. GTG turbulence prediction for flight level 430 above Iceland based on ECMWF forecasts valid at 1500 UTC together with the geopotential height (black solid lines). (a) GTG combination of MWT and CAT forecasts and (b) only the MWT forecast, respectively. The colored dotted line presents the in situ measured EDRs where the color coding refers to the turbulent severity resulting from the maximum value over a timeframe of about one minute. (c) Comparison of in situ measured EDR derived from vertical wind speed to MWT and CAT interpolated to the flight track.

This MW propagates through the troposphere across the tropopause into the lower stratosphere. In the lower stratosphere the negative vertical shear of the ambient flow causes a reduction in vertical wavelength (Fig. 14). Additionally, the wave-induced fluctuations in the horizontal wind speed reach similar magnitudes as the decreased ambient wind. As the ratio of perturbation to background wind approaches unity, a self-induced critical level develops for the MWs that leads to breaking MWs [cf. Fritts and Alexander (2003), Eq. (58)]. In the idealized EULAG simulations these turbulent spots can be identified as regions were locally isentropes steepen suggesting wave overturning and turbulent mixing. Together, the observations and the simulations suggest that the horizontal extent of the encountered breaking MW field is about 10 to $20 \mathrm{~km}$

The presence of strong turbulence is established by the large magnitudes of the TKE and EDR derived from the in situ observations. Especially the EDR indicates that moderate-to-severe turbulence was encountered by the aircraft in agreement with the pilot report. The observed encounter was a localized event related to vertically propagating MWs. The maximum turbulence covered a flight distance of about $20 \mathrm{~km}$ corresponding to $\approx 5 \%$ of the complete flight leg. Light-to-moderate turbulence was detected on about $15 \%$ of the leg. Here, the main flight direction was approximately against the mean wind and the 
a)

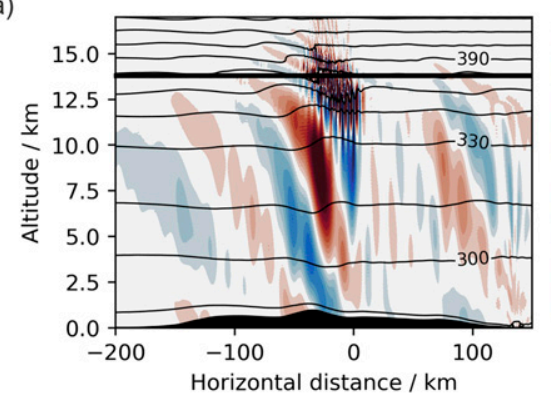

c)

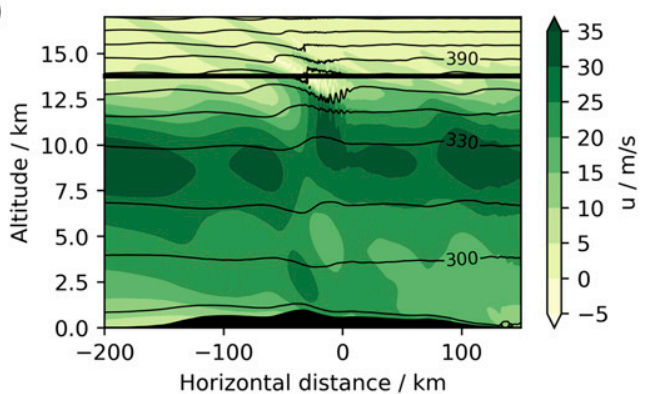

b)

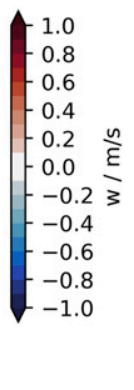

d)
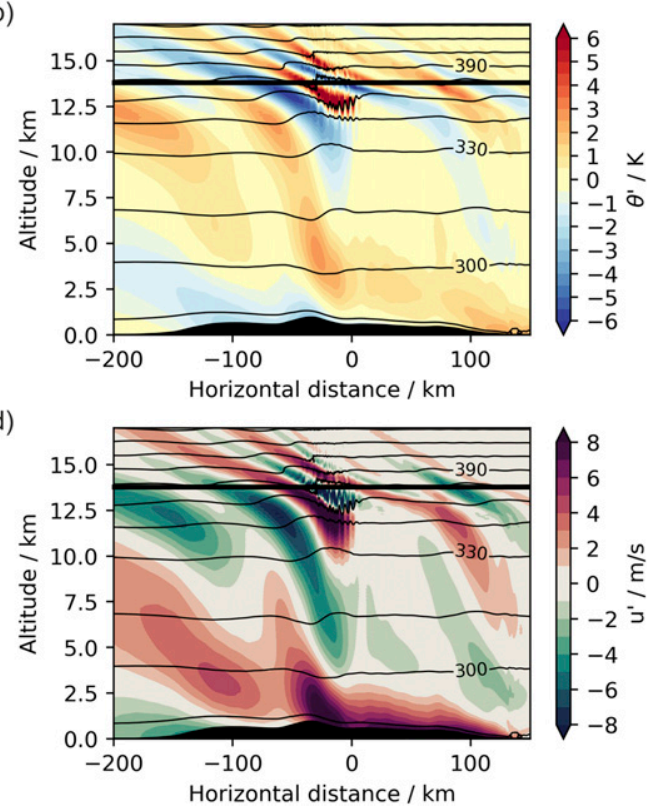

FIG. 14. Idealized EULAG simulations after $3 \mathrm{~h}$ of the (a) vertical wind speed, (b) potential temperature fluctuations, (c) horizontal wind speed, and (d) perturbation of the horizontal wind speed. Black contour lines are isentropic surfaces and the thick black line shows the altitude of HALO's flight track.

longitudinal component of EDR is on average larger compared to the transverse components. In Bramberger et al. (2018), the flight direction was transverse to the mean wind and the mean horizontal transverse EDR component was larger. Therefore, the studies indicate a dependence of the horizontal EDR component to the orientation of the flight direction with respect to the phase lines of the encountered MWs. This directional dependency was already found by Clodman (1957), who analyzed flights passing through turbulent fields at different headings.

With the knowledge of the idealized EULAG simulations, the large amplitudes in the vertical wind speed and the small-scale fluctuations superimposed on all measured meteorological parameters of HALO in situ measurements can be related to the breaking MW. Here, the amplitudes of the vertical wind speed are about $6.6 \mathrm{~m} \mathrm{~s}^{-1}$ in the EULAG simulations and only $\approx 13 \%$ smaller than observed ones. In the simulation domain, the horizontal extent of the simulated breaking region and the resulting downstream trail is only about half the size compared to the measurements. Also, the position of the turbulent region is not reproduced correctly. This might be due to the smoothed ECMWF topography used in EULAG simulations in which the slopes are not as steep as in reality, and therefore MWs with smaller amplitudes are excited, which in turn decreases the potential of breaking. Another possible explanation for this gap might be related to the simplified nature of 2D simulations. These shortcomings are addressed in a follow-up study.

Taking into account French Falcon in situ measurements reveals additional features of the observed atmospheric structures. Upstream of the turbulence encounter the meteorological parameters show similar wavelike structures with a comparable amplitude where the phase lines are tilted upstream when combining the observations. At the turbulence encounter, the temperature and horizontal wind suggest an anticorrelated structure. While the meridional wind increases to about $40 \mathrm{~m} \mathrm{~s}^{-1}$ in the French Falcon observations, it decreases to $0 \mathrm{~m} \mathrm{~s}^{-1}$ in the HALO observations. Together with the EULAG simulations our analysis suggests that HALO flew through the center of the MW breaking region while the French Falcon flew below this area. Here, the observations and simulations indicate that the vertical extent of the breaking region is about $2 \mathrm{~km}$. Considering the maximum vertical wind speeds, the breaking area at around $65^{\circ} \mathrm{N}$ appears to be tilted upstream with altitude. This tilting is also reproduced in the idealized EULAG 2D simulations. The decrease of the maximum observed vertical wind from about $7.6 \mathrm{~m} \mathrm{~s}^{-1}$ to about $3.4 \mathrm{~m} \mathrm{~s}^{-1}$ can indicate that the turbulence is reduced at the lower end of the breaking region compared to the center. However, it is also possible that vertical wind is underestimated due to the coarser resolution of $1 \mathrm{~Hz}$.

Also, analysis of the Eliassen-Palm relation based on the in situ measurements suggests that HALO was 
passing through a region dominated by nonlinear processes in several ways. On the one hand, the legintegrated $\mathrm{EF}_{z}$ is by $40 \%$ smaller than the respective UMF. On the other hand, an anticorrelation of $\mathrm{EF}_{z}$ and UMF was observed at and downstream of the turbulence encounter. In the framework of the Eliassen-Palm theory the energy fluxes $\mathrm{EF}_{z}$ and UMF are equal for freely vertically upward-propagating MWs in steady flow with no critical layers. Furthermore, the change in sign in the turbulent-scale energy fluxes (Fig. 8b) indicates the observation of an overturning wave. That way these results are further evidence for the prevalence of nonlinear processes in this altitude region.

Most of the detected significant energy fluxes are contained in scales that are referred to as the small and turbulent scales (Smith et al. 2016). In agreement with Smith et al. (2016) the detected energy fluxes are rather small with 1 to $2 \mathrm{~W} \mathrm{~m}^{-2}$ and are less than half of the typical energy fluxes observed during the Deep Propagating Gravity Wave Experiment (DEEPWAVE) $\left(4 \mathrm{~W} \mathrm{~m}^{-2}\right)$. Therefore, these are referred to as fluxless waves. In fact, Smith et al. (2016) argue that $\mathrm{EF}_{z}$ of about $1 \mathrm{~W} \mathrm{~m}^{-2}$ are at the detection threshold of in situ instrumentation. As the measurement uncertainty of HALO is similar to the NSF/NCAR Gulfstream-V (GV), the same threshold can be assumed in this study. During Gravity Wave Life Cycle Experiment I (GW-LCYCLE I), so-called fluxless waves were also observed (Wagner et al. 2017); however, the dominant scales of the horizontal wavelengths are with $15-20 \mathrm{~km}$ larger than the ones observed here.

The analyzed turbulence event took place in an atmospheric layer above the tropopause that is characterized by a rapidly decreasing horizontal wind with altitude until a wind minimum is reached. This layer, called the "valve layer" (Kruse and Smith 2015), was observed on numerous occasions in New Zealand during DEEPWAVE as well as above Japan in middle- and upper-atmosphere (MU) radar measurements (Sato 1990). Satomura and Sato (1999) showed in their numerical study that such a layer is prone to $\mathrm{GW}$ breaking due to convective instabilities. Also, Doyle et al. (2000) found most pronounced $\mathrm{GW}$ breaking in an altitude region from 13 to $16 \mathrm{~km}$ and 18 to $20 \mathrm{~km}$. Together with the results of this study the questions may be raised if such layers generally enhance occurrence of nonlinear processes, how these layers depend on the forcing at ground levels and if consequently those altitude regions are more hazardous to aviation.

Surprisingly, it was rather the larger-scale GWs with a horizontal wavelength of about $20 \mathrm{~km}$ downstream of the turbulent region that caused the necessity of pilot's intervention than the turbulence encounter itself.
Aircraft flying at this altitude have an increasingly narrow range of true airspeeds or Mach numbers within which they can fly stably (Bramberger et al. 2018). If variations of the longitudinal wind component vary abruptly enough along the flight track so that the autopilot system cannot maintain the aircraft's Mach number, then these wind speed variations can cause the true airspeed of the aircraft to be reduced below the stall speed or increased above its critical Mach number. Here, it appears that the observed breaking mountain wave caused changes in the horizontal wind speed that the autopilot could not automatically control, leading to either full acceleration or deceleration of the aircraft. Therefore, the pilot had to switch off the autothrottle system when entering this area. The main scale of the longitudinal wind speed in this area component is about 10 to $20 \mathrm{~km}$, which indicates that aircraft flying at this altitude region might react especially sensitive to atmospheric modulations at this scale. The altitude changes of the aircraft of about $\pm 50 \mathrm{~m}$ within approximately $15 \mathrm{~s}$ can be related to the breaking at about $65^{\circ} \mathrm{N}$ with large amplitudes in the vertical wind.

Forecasts of the ECMWF IFS reproduce the observed mesoscale structures very well compared to HALO and French Falcon in situ observations. With a mean difference of about $0.1 \mathrm{~K}$ for the French Falcon the potential temperature forecasts agree almost perfectly with the observations. Also, the structure of both horizontal wind components is forecasted very well. Thus, the analysis suggests that ECMWF IFS forecasts are a valuable source to determine background conditions for GW propagation.

However, Doyle et al. (2011) found that prediction of MW breaking and the consequent turbulence is challenging even for numerical models with a horizontal resolution of $1 \mathrm{~km}$. For this case, the largely empirical GTG turbulence forecasts predicted the magnitude of the detected turbulence at about the right location however, they show a tendency to overpredict the turbulence magnitude for large areas. Additionally, the observed spatial intermittency of the turbulent field is not reproduced as the forecasted turbulent areas are too large due to either inadequate resolution of the input NWP or smoothing of GTG diagnostics.

Acknowledgments. Part of this research was funded by the German research initiative "Role of the Middle Atmosphere in Climate (ROMIC/01LG1206A)" funded by the German Ministry of Research and Education in the project "Investigation of the life cycle of GWs (GW-LCYCLE)" and by the Deutsche Forschungsgemeinschaft (DFG) via the Project MS-GWaves (GW-TP/DO 1020/9-1, PACOG/RA 1400/6-1). Access to the ECMWF data was possible through the special 
project "HALO Mission Support System." Data of HALO's Quick Access Recorder were kindly provided by Kevin Raynor and Christoph Grad of the flight experiments department of DLR. Data of the French Falcon from SAFIRE are kindly provided by Gwendal Rivière, Julien Delanoë, and Jean-Claude Etienne. Observations of the French Falcon were conducted in the frame of the EPATAN-ESA/CNES/EUFAR/INSU projects. We thank three anonymous reviewers whose comments helped to improve the manuscript.

\section{REFERENCES}

Aebischer, U., and C. Schär, 1998: Low-level potential vorticity and cyclogenesis to the lee of the Alps. J. Atmos. Sci., 55, 186-207, https://doi.org/10.1175/1520-0469(1998) 055<0186:LLPVAC $>2.0$. CO; 2 .

Bacmeister, J. T., and M. R. Schoeberl, 1989: Breakdown of vertically propagating two-dimensional gravity waves forced by orography. J. Atmos. Sci., 46, 2109-2134, https://doi.org/ 10.1175/1520-0469(1989)046<2109:BOVPTD>2.0.CO;2.

,-- , L. R. Lait, P. A. Newman, and B. Gary, 1990: ER-2 mountain wave encounter over Antarctica: Evidence for blocking. Geophys. Res. Lett., 17, 81-84, https://doi.org/10.1029/ GL017i001p00081.

Bougeault, P., A. J. Clar, B. Benech, B. Carissimo, J. Pelon, and E. Richard, 1990: Momentum budget over the Pyrénées: The PYREX experiment. Bull. Amer. Meteor. Soc., 71, 806-818, https://doi.org/10.1175/1520-0477(1990)071<0806:MBOTPT> 2.0.CO;2.

— over a major mountain range: First results of the PYREX field program. Ann. Geophys., 11, 395-418.

— Bull. Amer. Meteor. Soc., 82, 433-462, https://doi.org/10.1175/ 1520-0477(2001)082<0433:TMSOP > 2.3.CO;2.

Bramberger, M., and Coauthors, 2017: Does strong tropospheric forcing cause large-amplitude mesospheric gravity waves? A DEEPWAVE case study. J. Geophys. Res. Atmos., 122, 11 422-11 443, https://doi.org/10.1002/2017JD027371.

—, A. Dörnbrack, H. Wilms, S. Gemsa, K. Raynor, and R. Sharman, 2018: Vertically propagating mountain waves-A hazard for high-flying aircraft? J. Appl. Meteor. Climatol., 57, 1957-1975, https://doi.org/10.1175/JAMC-D-17-0340.1.

Champagne, F. H., 1978: The fine-scale structure of the turbulent velocity field. J. Fluid Mech., 86, 67-108, https://doi.org/ 10.1017/S0022112078001019.

Clark, T. L., and W. R. Peltier, 1984: Critical level reflection and the resonant growth of nonlinear mountain waves. J. Atmos. Sci., 41, 3122-3134, https://doi.org/10.1175/1520-0469(1984) 041<3122:CLRATR>2.0.CO;2.

—, W. D. Hall, R. M. Kerr, D. Middleton, L. Radke, F. M. Ralph, P. J. Neiman, and D. Levinson, 2000: Origins of aircraftdamaging clear-air turbulence during the 9 December 1992 Colorado downslope windstorm: Numerical simulations and comparison with observations. J. Atmos. Sci., 57, 1105-1131, https://doi.org/10.1175/1520-0469(2000)057<1105:OOADCA> 2.0.CO;2.

Clodman, J., 1957: Anisotropic high-level turbulence. Quart. J. Roy. Meteor. Soc., 83, 116-120, https://doi.org/10.1002/ qj.49708335511.
Cornman, L. B., 2016: Airborne in situ measurements of turbulence. Aviation Turbulence, R. Sharman and T. Lane, Eds., Springer, 97-119.

_ C. C. Morse, and G. Cunning, 1995: Real-time estimation of atmospheric turbulence severity from in-situ aircraft measurements. J. Aircr., 32, 171-177, https://doi.org/10.2514/3.46697.

Dörnbrack, A., 1998: Turbulent mixing by breaking gravity waves. J. Fluid Mech., 375, 113-141, https://doi.org/10.1017/ S0022112098002833.

_ , and T. Dürbeck, 1998: Turbulent dispersion of aircraft exhausts in regions of breaking gravity waves. Atmos. Environ., 32, 3105 3112, https://doi.org/10.1016/S1352-2310(97)00503-7.

—, S. Gisinger, M. C. Pitts, L. R. Poole, and M. Maturilli, 2017: Multilevel cloud structures over Svalbard. Mon. Wea. Rev., 145, 1149-1159, https://doi.org/10.1175/MWR-D-16-0214.1.

Doyle, J. D., and Coauthors, 2000: An intercomparison of modelpredicted wave breaking for the 11 January 1972 Boulder windstorm. Mon. Wea. Rev., 128, 901-914, https://doi.org/ 10.1175/1520-0493(2000)128<0901:AIOMPW>2.0.CO;2.

- M. A. Shapiro, Q. Jiang, and D. L. Bartels, 2005: Largeamplitude mountain wave breaking over Greenland. J. Atmos. Sci., 62, 3106-3126, https://doi.org/10.1175/JAS3528.1.

_- , and Coauthors, 2011: An intercomparison of T-REX mountain-wave simulations and implications for mesoscale predictability. Mon. Wea. Rev., 139, 2811-2831, https://doi.org/ 10.1175/MWR-D-10-05042.1.

Eliassen, A., and E. Palm, 1961: On the transfer of energy in stationary mountain waves. Geofys. Publ., 22 (3), 1-23.

Ellrod, G. P., and D. I. Knapp, 1992: An objective clear-air turbulence forecasting technique: Verification and operational use. Wea. Forecasting, 7, 150-165, https://doi.org/10.1175/ 1520-0434(1992)007<0150:AOCATF>2.0.CO;2.

Esselborn, M., M. Wirth, A. Fix, M. Tesche, and G. Ehret, 2008: Airborne high spectral resolution lidar for measuring aerosol extinction and backscatter coefficients. Appl. Opt., 47, 346358, https://doi.org/10.1364/AO.47.000346.

Fritts, D. C., and M. J. Alexander, 2003: Gravity wave dynamics and effects in the middle atmosphere. Rev. Geophys., 41, 1003, https://doi.org/10.1029/2001RG000106.

_ , and Coauthors, 2016: The Deep Propagating Gravity Wave Experiment (DEEPWAVE): An airborne and ground-based exploration of gravity wave propagation and effects from their sources throughout the lower and middle atmosphere. Bull. Amer. Meteor. Soc., 97, 425-453, https://doi.org/10.1175/ BAMS-D-14-00269.1.

Giez, A., C. Mallaun, M. Zöger, A. Dörnbrack, and U. Schumann, 2016: Comparison of static pressure from aircraft trailing cone measurements and numerical weather prediction analysis. AIAA Aerodynamic Measurement Technology and Ground Testing Conf., Washington, DC, AIAA, AIAA 2016-3707, https://doi.org/10.2514/6.2016-3707.

Grinstein, F. F., L. G. Margolin, and W. J. Rider, Eds., 2007: Implicit Large Eddy Simulation: Computing Turbulent Fluid Dynamics. Cambridge University Press, 561 pp.

Grubišić, V., and Coauthors, 2008: The Terrain-Induced Rotor Experiment: A field campaign overview including observational highlights. Bull. Amer. Meteor. Soc., 89, 1513-1534, https:// doi.org/10.1175/2008BAMS2487.1.

Heller, R., and Coauthors, 2017: Mountain waves modulate the water vapor distribution in the ULTS. Atmos. Chem. Phys., 17, 14 853-14 869, https://doi.org/10.5194/acp-17-14853-2017.

Hines, C. O., 1960: Internal atmospheric gravity waves at ionospheric heights. Can. J. Phys., 38, 1441-1481, https://doi.org/10.1139/p60-150. 
Hoblit, F. M., 1988: Gust Loads on Aircraft: Concepts and Applications. AIAA Education Series, American Institute of Aeronautics and Astronautics, 306 pp.

Hólm, E., R. Forbes, S. Lang, L. Magnusson, and S. Malardel, 2016: New model cycle brings higher resolution. ECMWF Newsletter, No. 147, ECMWF, Reading, United Kingdom, 14-19, http:// www.ecmwf.int/sites/default/files/elibrary/2016/16299-newsletterno147-spring-2016.pdf.

ICAO, 2001: Meteorological service for international air navigation. Annex 3, Convention on International Civil Aviation, ICAO International Standards and Recommended Practices, 4th ed. ICAO, 128 pp.

Jiang, Q., and J. D. Doyle, 2004: Gravity wave breaking over the central Alps: Role of complex terrain. J. Atmos. Sci., 61, 22492266, https://doi.org/10.1175/1520-0469(2004)061<2249: GWBOTC $>2.0 . \mathrm{CO} ; 2$.

Kim, J.-H., R. Sharman, M. Strahan, J. W. Scheck, C. Bartholomew, J. C. H. Cheung, P. Buchanan, and N. Gait, 2018: Improvements in nonconvective aviation turbulence prediction for the World Area Forecast System. Bull. Amer. Meteor. Soc., 99, 2295-2311, https://doi.org/10.1175/BAMS-D-17-0117.1.

Kruse, C. G., and R. B. Smith, 2015: Gravity wave diagnostics and characteristics in mesoscale fields. J. Atmos. Sci., 72, 43724392, https://doi.org/10.1175/JAS-D-15-0079.1.

Leutbecher, M., and H. Volkert, 2000: The propagation of mountain waves into the stratosphere: Quantitative evaluation of three-dimensional simulations. J. Atmos. Sci., 57, 3090-3108, https://doi.org/10.1175/1520-0469(2000)057<3090:TPOMWI> 2.0.CO;2.

Lilly, D. K., 1978: A severe downslope windstorm and aircraft turbulence event induced by a mountain wave. J. Atmos. Sci., 35, 59-77, https://doi.org/10.1175/1520-0469(1978)035<0059: ASDWAA $>2.0 . \mathrm{CO} ; 2$.

—, and E. J. Zipser, 1972: The front range windstorm of 11 January 1972 a meteorological narrative. Weatherwise, 25 , 56-63, https://doi.org/10.1080/00431672.1972.9931577.

Lindzen, R. S., 1967: Thermally driven diurnal tide in the atmosphere. Quart. J. Roy. Meteor. Soc., 93, 18-42, https://doi.org/ 10.1002/qj.49709339503.

MacCready, P. B., 1964: Standardization of gustiness values from aircraft. J. Appl. Meteor., 3, 439-449, https://doi.org/10.1175/ 1520-0450(1964)003<0439:SOGVFA > 2.0.CO;2.

Malardel, S., and N. P. Wedi, 2016: How does subgrid-scale parametrization influence nonlinear spectral energy fluxes in global NWP models? J. Geophys. Res. Atmos., 121, 5395-5410, https://doi.org/10.1002/2015JD023970.

Mallaun, C., A. Giez, and R. Baumann, 2015: Calibration of 3-D wind measurements on a single-engine research aircraft. Atmos. Meas. Tech., 8, 3177-3196, https://doi.org/10.5194/amt-8-3177-2015.

Mech, M., E. Orlandi, S. Crewell, F. Ament, L. Hirsch, M. Hagen, G. Peters, and B. Stevens, 2014: HAMP-The microwave package on the High Altitude and Long range research aircraft (HALO). Atmos. Meas. Tech., 7, 4539-4553, https:// doi.org/10.5194/amt-7-4539-2014.

Melchionna, S., M. Bauer, and G. Peters, 2008: A new algorithm for the extraction of cloud parameters using multipeak analysis of cloud radar data-First application and preliminary results. Meteor. Z., 17, 613-620, https://doi.org/10.1127/ 0941-2948/2008/0322.

Oncley, S. P., C. A. Friehe, J. C. Larue, J. A. Businger, E. C. Itsweire, and S. S. Chang, 1996: Surface-layer fluxes, profiles, and turbulence measurements over uniform terrain under near-neutral conditions. J. Atmos. Sci., 53, 1029-1044,
https://doi.org/10.1175/1520-0469(1996)053<1029:SLFPAT > 2.0.CO;2.

Peltier, W. R., and T. L. Clark, 1979: The evolution and stability of finite-amplitude mountain waves. Part II: Surface wave drag and severe downslope windstorms. J. Atmos. Sci., 36, 1498-1529, https://doi.org/10.1175/1520-0469(1979)036<1498: TEASOF $>2.0 . \mathrm{CO} ; 2$.

Piper, M., and J. K. Lundquist, 2004: Surface layer turbulence measurements during a frontal passage. J. Atmos. Sci., 61, 1768-1780, https://doi.org/10.1175/1520-0469(2004)061<1768: SLTMDA $>2.0 . \mathrm{CO} ; 2$.

Prusa, J. M., P. K. Smolarkiewicz, and A. A. Wyszogrodzki, 2008: EULAG, a computational model for multiscale flows. Comput. Fluids, 37, 1193-1207, https://doi.org/10.1016/ j.compfluid.2007.12.001.

Sato, K., 1990: Vertical wind disturbances in the troposphere and lower stratosphere observed by the MU radar. J. Atmos. Sci., 47, 2803-2817, https://doi.org/10.1175/1520-0469(1990) 047<2803:VWDITT>2.0.CO;2.

Satomura, T., and K. Sato, 1999: Secondary generation of gravity waves associated with the breaking of mountain waves. J. Atmos. Sci., 56, 3847-3858, https://doi.org/10.1175/1520-0469(1999) $056<3847$ :SGOGWA $>2.0 . \mathrm{CO} ; 2$.

Schäfler, A., and Coauthors, 2018: The North Atlantic Waveguide and Downstream Impact Experiment. Bull. Amer. Meteor. Soc., 99, 1607-1637, https://doi.org/10.1175/BAMS-D-17-0003.1.

Schär, C., and R. B. Smith, 1993: Shallow-water flow past isolated topography. Part I: Vorticity production and wake formation. J. Atmos. Sci., 50, 1373-1400, https://doi.org/10.1175/15200469(1993)050<1373:SWFPIT >2.0.CO;2.

Schmid, H., and A. Dörnbrack, 1999: Simulation of breaking gravity waves during the south foehn of January 7-13, 1996. Contrib. Atmos. Phys., 72, 287-301.

Sharman, R. D., and J. M. Pearson, 2017: Prediction of energy dissipation rates for aviation turbulence. Part I: Forecasting nonconvective turbulence. J. Climate Appl. Meteor., 56, 317337, https://doi.org/10.1175/JAMC-D-16-0205.1.

, C. Tebaldi, G. Wiener, and J. Wolff, 2006: An integrated approach to mid- and upper-level turbulence forecasting. Wea. Forecasting, 21, 268-287, https://doi.org/10.1175/WAF924.1.

, J. D. Doyle, and M. A. Shapiro, 2012a: An investigation of a commercial aircraft encounter with severe clear-air turbulence over western Greenland. J. Appl. Meteor. Climatol., 51, 42-53, https://doi.org/10.1175/JAMC-D-11-044.1.

, S. B. Trier, T. P. Lane, and J. D. Doyle, 2012b: Sources and dynamics of turbulence in the upper troposphere and lower stratosphere: A review. Geophys. Res. Lett., 39, L12803, https://doi.org/10.1029/2012GL051996.

— L. L. B. Cornman, G. Meymaris, J. Pearson, and T. Farrar, 2014: Description and derived climatologies of automated in situ eddy-dissipation-rate reports of atmospheric turbulence. J. Climate Appl. Meteor., 53, 1416-1432, https://doi.org/ 10.1175/JAMC-D-13-0329.1.

Smith, R. B., 1989: Hydrostatic airflow over mountains. Advances in Geophysics, B. Saltzman, Ed., Vol. 31, Academic Press, 141, https://doi.org/10.1016/S0065-2687(08)60052-7.

, B. K. Woods, J. Jensen, W. A. Cooper, J. D. Doyle, Q. Jiang, and V. Grubišić, 2008: Mountain waves entering the stratosphere. J. Atmos. Sci., 65, 2543-2562, https://doi.org/10.1175/ 2007JAS2598.1.

, and Coauthors, 2016: Stratospheric gravity wave fluxes and scales during DEEPWAVE. J. Atmos. Sci., 73, 2851-2869, https://doi.org/10.1175/JAS-D-15-0324.1. 
Strauss, L., S. Serafin, S. Haimov, and V. Grubišić, 2015: Turbulence in breaking mountain waves and atmospheric rotors estimated from airborne in situ and Doppler radar measurements. Quart. J. Roy. Meteor. Soc., 141,3207-3225, https:// doi.org/10.1002/qj.2604.

Thorpe, A. J., H. Volkert, and D. Heimann, 1993: Potential vorticity of flow along the Alps. J. Atmos. Sci., 50, 1573-1590, https://doi.org/ 10.1175/1520-0469(1993)050<1573:PVOFAT > 2.0.CO;2.

Torrence, C., and G. P. Compo, 1998: A practical guide to wavelet analysis. Bull. Amer. Meteor. Soc., 79, 61-78, https://doi.org/ 10.1175/1520-0477(1998)079<0061:APGTWA > 2.0.CO;2.

VanZandt, T. E., and D. C. Fritts, 1989: A theory of enhanced saturation of the gravity wave spectrum due to increases in atmospheric stability. Pure Appl. Geophys., 130, 399-420, https://doi.org/10.1007/BF00874466.

Večenaj, Ž., D. Belušić, V. Grubišić, and B. Grisogono, 2012: Alongcoast features of Bora-related turbulence. Bound.-Layer Meteor., 143, 527-545, https://doi.org/10.1007/s10546-012-9697-6.

Vinnichenko, N. K., N. Z. Pinus, S. M. Shmeter, and G. N. Shur, 1980: Turbulence in the Free Atmosphere. Plenum, 310 pp.
Wagner, J., and Coauthors, 2017: Observed versus simulated mountain waves over Scandinavia-Improvement of vertical winds, energy and momentum fluxes by enhanced model resolution? Atmos. Chem. Phys., 17, 4031-4052, https://doi.org/ 10.5194/acp-17-4031-2017.

Wedi, N. P., 2014: Increasing horizontal resolution in numerical weather prediction and climate simulations: Illusion or panacea? Philos. Trans. Roy. Soc., 372A, 20130289, https://doi.org/ 10.1098/RSTA.2013.0289.

Wirth, M., A. Fix, P. Mahnke, H. Schwarzer, F. Schrandt, and G. Ehret, 2009: The airborne multi-wavelength water vapor differential absorption lidar WALES: System design and performance. Appl. Phys., 96B, 201-213, https://doi.org/10.1007/ s00340-009-3365-7.

Woods, B. K., and R. B. Smith, 2010: Energy flux and wavelet diagnostics of secondary mountain waves. J. Atmos. Sci., 67, 3721-3738, https://doi.org/10.1175/2009JAS3285.1.

Worthington, R., 1998: Tropopausal turbulence caused by the breaking of mountain waves. J. Atmos. Sol.-Terr. Phys., 60, 1543-1547, https://doi.org/10.1016/S1364-6826(98)00105-9. 